\title{
Retrieval of radiative and microphysical properties of clouds from multispectral infrared measurements
}

\author{
Hironobu Iwabuchi ${ }^{1 *}$ D, Masanori Saito ${ }^{1}$, Yuka Tokoro1, Nurfiena Sagita Putri and Miho Sekiguchi ${ }^{2}$
}

\begin{abstract}
Satellite remote sensing of the macroscopic, microphysical, and optical properties of clouds are useful for studying spatial and temporal variations of clouds at various scales and constraining cloud physical processes in climate and weather prediction models. Instead of using separate independent algorithms for different cloud properties, a unified, optimal estimation-based cloud retrieval algorithm is developed and applied to moderate resolution imaging spectroradiometer (MODIS) observations using ten thermal infrared bands. The model considers sensor configurations, background surface and atmospheric profile, and microphysical and optical models of ice and liquid cloud particles and radiative transfer in a plane-parallel, multilayered atmosphere. Measurement and model errors are thoroughly quantified from direct comparisons of clear-sky observations over the ocean with model calculations. Performance tests by retrieval simulations show that ice cloud properties are retrieved with high accuracy when cloud optical thickness (COT) is between 0.1 and 10. Cloud-top pressure is inferred with uncertainty lower than $10 \%$ when COT is larger than 0.3. Applying the method to a tropical cloud system and comparing the results with the MODIS Collection 6 cloud product shows good agreement for ice cloud optical thickness when COT is less than about 5. Cloud-top height agrees well with estimates obtained by the $\mathrm{CO}_{2}$ slicing method used in the MODIS product. The present algorithm can detect optically thin parts at the edges of high clouds well in comparison with the MODIS product, in which these parts are recognized as low clouds by the infrared window method. The cloud thermodynamic phase in the present algorithm is constrained by cloud-top temperature, which tends not to produce results with an ice cloud that is too warm and liquid cloud that is too cold.
\end{abstract}

Keywords: Cloud optical thickness, Cloud-top height, Effective particle radius, Ice cloud, Optimal estimation method, Satellite remote sensing

\section{Introduction}

Clouds play a vital role in regulating the Earth's radiation budget, through shortwave cooling and longwave warming effects (Ramanathan et al. 1989). The cloud radiative effects depend on the type of cloud, and thus, the radiation budget is controlled by the occurrence of various types of clouds (Hartmann et al. 1992), which complicates our understanding of cloud roles in the climate system. In particular, the radiative effects of ice clouds are not well understood, partly because the optical

\footnotetext{
* Correspondence: hiroiwa@m.tohoku.ac.jp

${ }^{1}$ Center for Atmospheric and Oceanic Studies, Graduate School of Science, Tohoku University, 6-3 Aoba, Aramakiaza, Aoba-ku, Sendai, Miyagi 980-8578, Japan

Full list of author information is available at the end of the article
}

properties of ice clouds are not well quantified (Baran 2009), which is a major source of uncertainty in ice cloud representations in global climate models. There are discrepancies in satellite observation climatology of ice clouds, and improvement of ice cloud processes is still a challenge (e.g., Waliser et al. 2009). Climatology and spatial and temporal variations of clouds on various scales are also important to understand cloud response and feedback in climate systems. Satellite remote sensing can provide constraints for global cloud properties that are useful for developing cloud parameterizations. Macroscopic, microphysical, and optical properties are generally used in satellite remote sensing of clouds. There are specialized methods for each property, including cloud fraction, cloud-top properties (temperature/ 
pressure/height), cloud thermodynamic phase, cloud optical thickness (COT), and cloud-particle effective radius (CER).

There are two passive remote sensing methods that are commonly used for cloud optical and microphysical properties: infrared (IR) window (split-window) (Inoue 1985; Parol et al. 1991; Giraud et al. 1997) and visible/ shortwave IR (VIS/SWIR) bispectral (Nakajima and King 1990) approaches. IR window cloud retrieval is suitable for optically thin high clouds with COT of 0.1-5 (e.g., Garnier et al. 2012), whereas the VIS/SWIR method is suitable for optically thick clouds with COT greater than 1 (Nakajima and King 1990; Platnick et al. 2003). We have developed an IR method to retrieve COT and CER by using the $8.5,11$, and $12 \mu \mathrm{m}$ bands of the moderate resolution imaging spectroradiometer (MODIS) onboard the Aqua satellite (Iwabuchi et al. 2014). In this method, inversion was based on the optimal estimation method (Rodgers 2000), which simultaneously fits the physics model to measurements and diagnoses rigorous uncertainties and retrieval quality. The optimal estimation method has been used widely for cloud remote sensing (Cooper et al. 2003; Heidinger and Pavolonis 2009; Watts et al. 2011; Walther and Heidinger 2012; Poulsen et al. 2012; Sourdeval et al. 2013; 2015; Wang et al. 2016). In a previous work (Iwabuchi et al. 2014), cloud retrieval was applied only to the ice phase cloud, and the a priori cloud-top temperature (CTT) was independently estimated by the $\mathrm{CO}_{2}$ slicing technique (Menzel et al. 2008) in the MODIS operational product. Thus, the retrieval was strongly constrained by cloud-top prior information and affected by the CTT accuracy in the MODIS product. Because the CTT retrieval itself can depend on COT and microphysical properties, the overall retrieval performance can be obtained if the cloud-top height $(\mathrm{CTH}), \mathrm{COT}$, and effective radius are retrieved simultaneously from the window and absorption bands.

In addition, the cloud thermodynamic phase is important because liquid and ice clouds play different roles in regulating the Earth's radiation budget and hydrological cycle. Although cloud retrieval using passive sensors usually assumes single-layer ice or liquid clouds, it leads to substantial errors in estimated cloud optical and microphysical properties if there is a multilayer cloud system or if the assumed cloud phase is wrong (Davis et al. 2009). Recent studies using active remote sensing from CloudSat and Cloud-Aerosol Lidar and Infrared Pathfinder Satellite Observation (CALIPSO) satellites have obtained a globally averaged multilayered cloud occurrence of 25-28\% (Li et al. 2015). A cloud analysis algorithm should include methods for detection and property retrieval of multilayered cloud systems and determination of the cloud phase.
In this paper, an optimal estimation-based cloud retrieval algorithm is presented, where COT, CER, cloud-top pressure (CTP), and surface temperatures are simultaneously retrieved from measurements in ten thermal IR (TIR) bands of MODIS including the window and $\mathrm{CO}_{2}$ and water vapor absorption bands. Combined use of TIR bands enables the cloud thermodynamic phase to be distinguished and allows the method to be used for multilayer clouds, as previous pioneering studies suggest. The cloud retrieval algorithm is developed as part of the Integrated Cloud Analysis System (ICAS), which we develop in this study. This paper is organized as follows. The "Methods" section describes the source data used for cloud analysis, the cloud retrieval algorithm, the forward model, and the measurement and model errors, which are thoroughly quantified by model-tomodel and model-to-observation comparisons. In the "Results and Discussion" section, retrieval errors are evaluated based on retrieval simulations in idealized cases, to understand the advantages and limitations of the algorithm. The algorithm is applied to a MODIS granule, and the retrieved cloud properties are compared with the MODIS Collection 6 (C6) operational product. The conclusion is given in the "Conclusions" section.

\section{Methods/Experimental}

\section{Source data}

The measurement data used in this study are from the level 1B product of MODIS onboard the Aqua satellite. MODIS has a swath of $2330 \mathrm{~km}$, and a granule every 5 min covers an area of $2330 \times 2030 \mathrm{~km}$. TIR bands have a $1 \mathrm{~km}$ resolution, and the ten TIR bands are summarized in Table 1. In addition to bands 29, 31, and 32 in the atmospheric window, the bands used include ozone absorption band $30(9.6 \mu \mathrm{m})$, water vapor absorption bands 27 and 28, and carbon dioxide absorption bands 32-36. The spectral radiance of each band is converted to the brightness temperature (BT). The band mean Planck function for temperature $T$ is defined as

$$
\bar{B}(T)=\frac{\int_{0}^{\infty} B(\lambda, T) \phi(\lambda) d \lambda}{\int_{0}^{\infty} \phi(\lambda) d \lambda},
$$

where $B$ is the Planck function, $\lambda$ is the wavelength, and $\phi$ is the response function of each MODIS band. The band mean Planck function is precalculated for different temperatures, and the Akima interpolation (Akima 1970) is used to calculate the function or its inverse function, the BT, from the look-up table.

The source data used in ICAS are summarized in Table 2. Meteorological field data, including temperature 
Table 1 Characteristics of MODIS bands used in this study

\begin{tabular}{llll}
\hline Band & Center wavelength $(\mu \mathrm{m})$ & Band range $(\mu \mathrm{m})$ & Absorbers $^{\mathrm{a}}$ \\
\hline 27 & 6.78683 & $6.535-6.895$ & $\mathrm{H}_{2} \mathrm{O}$ \\
28 & 7.34963 & $7.175-7.475$ & $\mathrm{H}_{2} \mathrm{O}, \mathrm{CH}_{4}$ \\
29 & 8.55511 & $8.400-8.700$ & $\mathrm{H}_{2} \mathrm{O}, \mathrm{N}_{2} \mathrm{O}, \mathrm{CH}_{4}$ \\
30 & 9.72374 & $9.580-9.880$ & $\mathrm{H}_{2} \mathrm{O}, \mathrm{CO}_{2}, \mathrm{O}_{3}$ \\
31 & 11.026 & $10.780-11.280$ & $\mathrm{H} \mathrm{O}, \mathrm{CO}_{2}$ \\
32 & 12.0423 & $11.770-12.270$ & $\mathrm{H}_{2} \mathrm{O}, \mathrm{CO}_{2}$ \\
33 & 13.3648 & $13.185-13.485$ & $\mathrm{H}_{2} \mathrm{O}, \mathrm{CO}_{2}, \mathrm{O}_{3}$ \\
34 & 13.686 & $13.485-13.785$ & $\mathrm{H}_{2} \mathrm{O}, \mathrm{CO}_{2}, \mathrm{O}_{3}$ \\
35 & 13.9252 & $13.785-14.085$ & $\mathrm{H}_{2} \mathrm{O}, \mathrm{CO}_{2}, \mathrm{O}_{3}$ \\
36 & 14.2153 & $14.085-14.385$ & $\mathrm{H}_{2} \mathrm{O}, \mathrm{CO}_{2}, \mathrm{O}_{3}$ \\
\hline
\end{tabular}

${ }^{a}$ The major absorbing gas is shown in italics

and ozone and water vapor mixing ratios, are obtained by interpolation in the space-time domain from the Modern-Era Retrospective analysis for Research and Applications (MERRA) product, IAU 3D assimilated state on pressure, which has a horizontal resolution of $1.25^{\circ} \times 1.25^{\circ}, 42$ pressure levels, and a time interval of $3 \mathrm{~h}$. The MERRA product is the atmosphere re-analysis product of the National Aeronautics and Space Administration, Goddard Earth Observing System Model, Version 5 (GEOS-5) with its atmospheric data assimilation system (Rienecker et al. 2011). Concentrations of carbon dioxide $\left(\mathrm{CO}_{2}\right)$, methane $\left(\mathrm{CH}_{4}\right)$, and nitrous oxide $\left(\mathrm{N}_{2} \mathrm{O}\right)$ are global monthly mean values provided from the World Data Center for Greenhouse Gases of the World Meteorological Organization Global Atmosphere Watch program (Tsutsumi et al. 2009).

Sea surface temperature data are from the MODIS 8 day mean level 3 product that is based on the TIR split window method (Brown et al. 1999). The rootmean-square error (RMSE) of SST by the split window method is evaluated as $0.35 \mathrm{~K}$. Sea surface emissivity is determined by using the Fresnel equations for a flat sea surface based on the complex refractive index and the satellite zenith angle. The effects of a rough surface, including the effects of multiple reflection and wind direction, are sufficiently small for our purposes when the satellite zenith angle is $60^{\circ}$ or less (Masuda 2012).

Table 2 Summary of MODIS operational product data used in the retrieval algorithm

\begin{tabular}{llll}
\hline Quantity & Source & $\begin{array}{l}\text { Spatial } \\
\text { resolution }\end{array}$ & $\begin{array}{l}\text { Temporal } \\
\text { resolution }\end{array}$ \\
\hline Atmospheric profile & MERRA & $1.25^{\circ}, 42$ levels & $3 \mathrm{~h}$ \\
Sea surface temperature & MODIS L3 & $0.4167^{\circ}$ & 8 day mean \\
Land surface temperature & MODIS L3 & $0.05^{\circ}$ & 8 day mean \\
Land surface emissivity & BFED & $0.05^{\circ}$ & Monthly \\
Trace gas concentration & Climatology & Global & Monthly \\
\hline
\end{tabular}

The complex refractive index of seawater is synthesized from that of pure water based on Downing and Williams (1975) with a correction for the salinity effect based on Friedman (1969).

The land surface temperature is from the MODIS land 8 day mean level 3 product (MYD11C2), which is based on the day-night algorithm (Wan and Li 1997). For each day and night satellite overpass, the 8 day mean values are available in the product. In the present study, the land surface temperature is temporarily interpolated by considering the diurnal variation. The RMSE of the land surface temperature is less than $1 \mathrm{~K}$ (Wan et al. 2004; Wang et al. 2008). The land surface emissivity is from the baseline-fit emissivity database (BFED) monthly mean product (Seemann et al. 2008). Spectral interpolation is used to infer land surface emissivity in the MODIS bands, assuming that the emissivity is linear to the wavelength as recommended by the BFED documentation. The RMSE of land surface emissivity in the BFED is 0.01 or less in the IR window region and about $0.015-0.025$ in the other TIR bands.

\section{Forward model}

A physics-based forward model is developed and used in the cloud retrieval algorithm. The forward model takes auxiliary data for the atmospheric profile and background surface properties mentioned above, and it computes the BTs and their partial derivatives with respect to several atmospheric and surface variables. The radiative transfer is calculated by using the correlated $k$-distribution (CKD) method with six quadrature points for each band. The optimization method of Sekiguchi and Nakajima (2008) is used to determine the CKD coefficients from line-by-line radiative transfer calculations with the HITRAN2012 database (Rothman et al. 2013) and the continuum absorption model (Mlawer et al. 2012). Modeled gas species include water vapor, carbon dioxide, ozone, nitrous oxide, carbon monoxide, and methane.

The bulk optical properties of clouds are precalculated and tabulated for ice and liquid clouds with different particle size distributions and ice crystal habit distributions considering the spectral response function of MODIS spectral bands. In the forward model calculation, the optical properties are interpolated with respect to the CER from the look-up table by using the Akima interpolation. The optical properties of water droplets are computed by the Lorenz-Mie theory. The optical properties of ice particles are obtained from a database published by Yang et al. (2013), who used a combination of the discrete dipole approximation and the improved geometrical optics method for randomly oriented ice crystals of various shapes. Several models of particle habit distribution are incorporated into the model, 
including solid column, plate, column aggregate, the general habit mixture (Baum et al. 2011; Cole et al. 2013), and the two-habit model (Liu et al. 2014), with different degrees of surface roughness. In the present study, the column aggregate model with very rough surfaces is used because it is assumed in obtaining the MODIS C6 cloud product. TIR measurements are not strongly sensitive to the ice habit assumptions (Cooper et al. 2006).

Radiative transfer in a plane-parallel multilayered atmosphere is solved by the two-stream approximation (Nakajima et al. 2000) with the delta-M method (Wiscombe 1977). Solutions of the two-stream approximation are upward and downward irradiances at layer boundaries, from which the radiances at the top of the atmosphere in arbitrary directions can be calculated. The radiative transfer equation for a single homogeneous layer is written as

$$
\mu \frac{d I(\tau, \mu)}{d \tau}=I(\tau, \mu)-\left[\frac{\varpi}{2 \pi}\left\{F^{\downarrow}\left(1-\frac{3}{2} g \mu\right)+F^{\uparrow}\left(1+\frac{3}{2} g \mu\right)\right\}+(1-\varpi) B(\tau)\right]
$$

where $I(\tau, \mu)$ is radiance at optical depth $\tau$ from the top of the layer in a direction with $\mu=\cos \theta$ for view zenith angle $\theta, \varpi$ is the single-scattering albedo, $g$ is the asymmetry factor, and $F^{\uparrow}$ and $F^{\downarrow}$ are upward and downward irradiances, respectively. The second term on the right-hand side of (2) is the radiative source function, $J(\tau, \mu)$, which is here approximated to be linear to $\tau$, as

$$
J(\tau, \mu)=a(\mu) \tau+b(\mu),
$$

where $a$ and $b$ are coefficients determined by the source function values at the layer boundaries. Thus, upward radiance emergent from this layer in the $\mu$ direction at the top of layer with optical depth $\Delta \tau$ is analytically solved as

$$
\begin{aligned}
I_{\mathrm{top}}(\mu)= & I_{\mathrm{bot}}(\mu) e^{-\frac{\Delta \tau}{\mu}}-(a(\mu) \Delta \tau+a(\mu) \mu+b(\mu)) e^{-\frac{\Delta \tau}{\mu}} \\
& +a(\mu) \mu+b(\mu)
\end{aligned}
$$

Total radiance at the top of atmosphere is computed by the sum of components emergent from all atmospheric layers and the background surface. Band mean radiance calculated by integration over the CKD terms is converted to the BT.

The error of this approximate radiative transfer model is evaluated by comparing the model with an accurate model based on the discrete ordinate method for a variety of atmosphere and cloud states. Correction formulae based on a cubic polynomial for BT bias are developed for each band. After the bias correction, the RMSE reaches a maximum of $0.3 \mathrm{~K}$ in band 29 , where the scattering effect is strong compared with other TIR bands. The two-stream approximation enables fast calculations, whereas the errors from the radiative transfer approximation are sufficiently small. For cloud retrieval, uncertainties in atmospheric profile and background surface properties are a major source of errors in the forward model.

Figure 1 shows the $\mathrm{BT}$ and $\mathrm{BT}$ differences (BTDs) at the split window band, calculated for liquid and ice clouds with a CTT of $247 \mathrm{~K}$ in a tropical atmosphere with a sea surface temperature of $300 \mathrm{~K}$. As suggested by prior studies, a combination of multiple bands in the window region of $8-13 \mu \mathrm{m}$ allows the CER to be inferred. Measurements in these bands are sensitive to clouds with a COT of $0.05-20$ and an effective radius of $3-100 \mu \mathrm{m}$ for ice clouds. The COT is defined at a wavelength of $550 \mathrm{~nm}$ throughout this paper. The water phase (liquid/ice) is moderately important to the spectral differences in BTs in the split window. Absorption by ice and liquid particles becomes stronger at wavelengths longer than $11 \mu \mathrm{m}$, although the ice and liquid phases have different spectral dependences of absorption, which means that the cloud thermodynamic phase can be determined from these bands.

\section{Retrieval algorithm}

The optimal estimation method (Rodgers 2000) is used to solve an inverse problem. The method fits the forward model to the measurement under constraints by an a priori probability distribution of the state vector in the forward model. Defining state vector $\mathbf{x}$, measurement vector $\mathbf{y}$ with the BTs in the MODIS TIR bands as elements, and the model parameter vector $\mathbf{b}$, the problem to be solved is written as

$$
\mathbf{y}=\mathbf{F}(\mathbf{x}, \mathbf{b})+\mathbf{e},
$$

where $\mathbf{F}$ is the forward model, and $\mathbf{e}=\mathbf{y}-\mathbf{F}(\mathbf{x}, \mathbf{b})$ is a measurement-model error vector. A cost function is given by

$$
J(\mathbf{x})=[\mathbf{y}-\mathbf{F}(\mathbf{x}, \mathbf{b})]^{\mathrm{T}} S_{\mathrm{e}}^{-1}[\mathbf{y}-\mathbf{F}(\mathbf{x}, \mathbf{b})]+\left[\mathbf{x}-\mathbf{x}_{\mathrm{a}}\right]^{\mathrm{T}} S_{\mathrm{a}}^{-1}\left[\mathbf{x}-\mathbf{x}_{\mathrm{a}}\right],
$$

where $S_{\mathrm{a}}$ is an error covariance matrix of the a priori $\mathbf{x}_{\mathrm{a}}$, and $S_{\mathrm{e}}$ is a measurement-model error covariance matrix. The Levenberg-Marquardt method is used to obtain a minimized $J$, at which the solution converges. The final value of $J$ is the retrieval cost, which represents the degree of fit between the model and measurement. The criterion that $J$ is sufficiently small with an optimal solution is set as $J<2 m$, where the $m$ is a number of the observation vector elements. A feature of the optimal estimation is that the uncertainty of the solution can be diagnosed quantitatively with an 

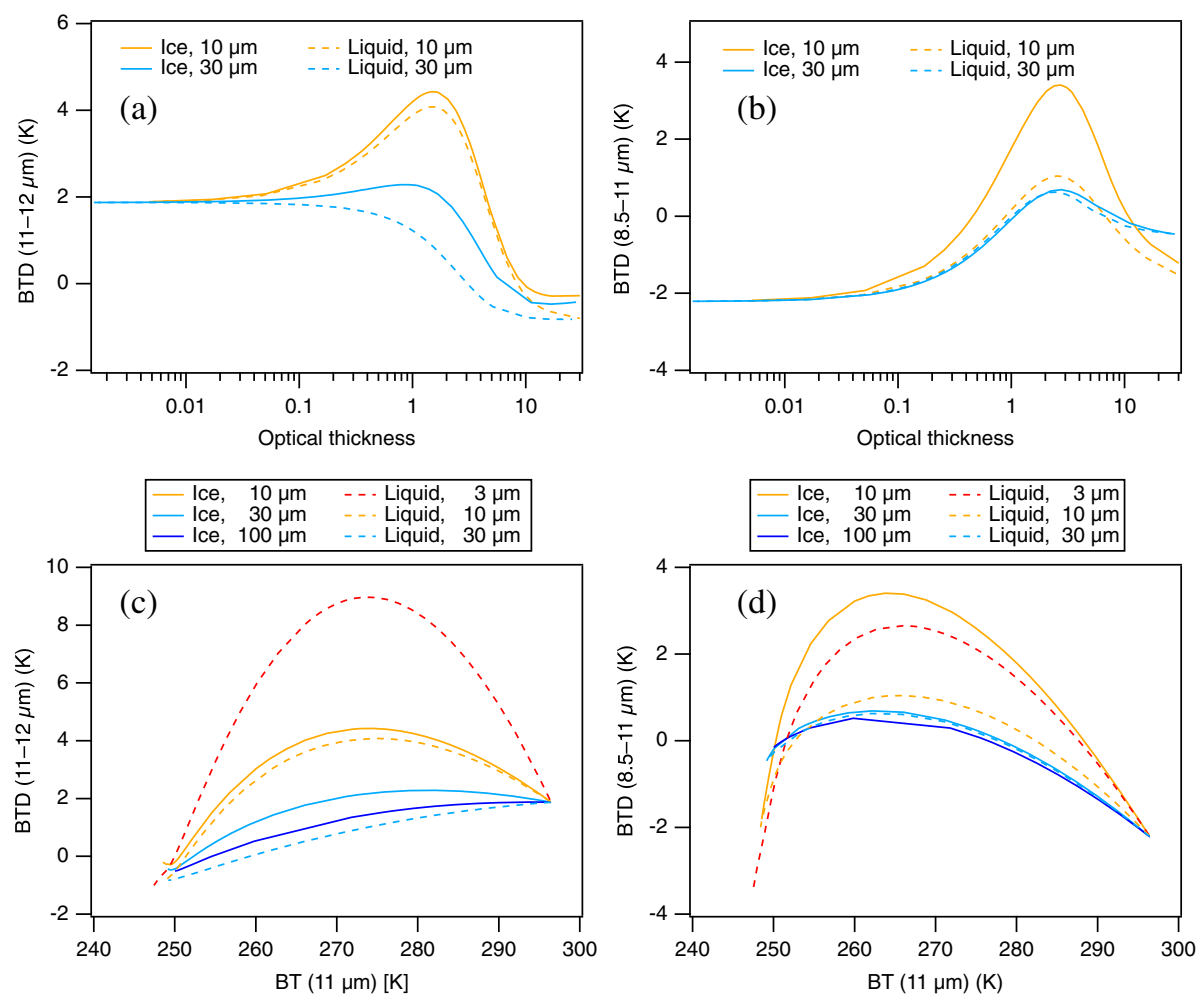

Fig. 1 Sensitivities of the split window bands to COT, effective particle radius, and cloud thermodynamic phase. Theoretical relationships of BTDs with $\operatorname{COT}(\mathbf{a}, \mathbf{b})$ and BT $(\mathbf{c}, \mathbf{d})$ in the $11 \mu \mathrm{m}$ band. Calculations are shown for different effective particle radii for ice and liquid clouds with the same CTTs of $247 \mathrm{~K}$ in a typical tropical atmosphere with sea surface temperature of $300 \mathrm{~K}$. The two-habit model from Liu et al. (2014) is assumed for ice particles

error covariance matrix. In addition, diagnostics of the estimation quality, such as the degree of freedom for signal (DOFS) and the information content, are obtained.

The cloud inversion is tried first with a single-layer cloud. If an optimal solution is obtained, the singlelayer assumption is accepted. Otherwise, an inversion with a double-layer assumption is tried. A double-layer cloud solution is accepted if $J$ is smaller than that of the single-layer assumption and the COT of the upper cloud is less than 8 . This is because TIR measurements lose sensitivity to the lower cloud under the doublelayer cloud assumption if the upper COT is more than about 8 . The state vector includes cloud properties such as cloud water path (CWP), CER, CTP, and background surface temperature in single-layer cloud cases. With nonlinearity in mind, logarithms of CTP, CWP, and CER are elements of the state vector. The toppressure of the lower cloud is inferred in double-layer clouds, instead of background surface temperature, as a similar double-layer cloud retrieval is proposed by Watts et al. (2011).

The cloud layer is assumed to be composed of either liquid droplets or ice particles. The ice (liquid) phase is accepted if an optimal solution is obtained with CTT below a threshold temperature, $T_{\mathrm{f}}=-38{ }^{\circ} \mathrm{C}$ (above $T_{\mathrm{m}}=$ $0{ }^{\circ} \mathrm{C}$ ). If the CTT is between $T_{\mathrm{f}}$ and $T_{\mathrm{m}}$, or an optimal solution is not obtained, then inversion with the other cloud phase assumptions are tried. Final judgment of cloud phase is to select a lower cloud phase cost function, $R$, of

$$
R=\frac{P_{1}}{V_{1}}+\frac{P_{2}}{V_{2}}+\frac{P_{3}}{V_{3}}+\frac{J}{J_{\mathrm{opt}}}
$$

where weighting coefficients are set as $V_{1}=8 \mathrm{~K}^{2}, V_{2}=$ $30^{2} \mathrm{~K}^{2}, V_{3}=0.3^{2}$, and $J_{\text {opt }}=2 \mathrm{~m}$. As shown in Fig. 1 , the split window bands are sensitive to the cloud phase. Thus, $P_{1}$ is the sum of squares of BTD between the observation and model at the split window bands at wavelengths of $8.5,11$, and $12 \mu \mathrm{m}$

$$
\begin{aligned}
P_{1}= & \left(\text { BTD }_{8.5-11, \mathrm{obs}}-\mathrm{BTD}_{8.5-11, \mathrm{mdl}}\right)^{2} \\
& +\left(\mathrm{BTD}_{11-12, \mathrm{obs}}-\mathrm{BTD}_{11-12, \mathrm{mdl}}\right)^{2}
\end{aligned}
$$

where subscripts "obs" and "mdl" denote the observation and model, respectively. Because the CTT is a main factor that prescribes cloud phase, $P_{2}$ increases with increasing deviation of CTT $\left(T_{\text {top }}\right)$ from a critical 
temperature, $T_{\mathrm{c}, \text { ice }}=-15{ }^{\circ} \mathrm{C}$ for ice and $T_{\mathrm{c}, \text { liq }}=-23{ }^{\circ} \mathrm{C}$ for liquid, as

$$
P_{2}=\left\{\begin{array}{l}
{\left[\min \left(0, T_{\text {top }}-T_{\text {c,liq }}\right)\right]^{2} \text { for liquid }} \\
{\left[\max \left(0, T_{\text {top }}-T_{\mathrm{c}, \text { ice }}\right)\right]^{2} \text { for ice }}
\end{array} .\right.
$$

However, CTT is uncertain when CTP retrieval is uncertain. Thus, $P_{3}$ in Eq. (7) is the error variance of the logarithm of CTP. Finally, an index of the cloud phase, $Q$, is calculated as

$$
Q=1+\frac{R_{\mathrm{liq}}^{2}}{R_{\mathrm{liq}}^{2}+R_{\mathrm{ice}}^{2}},
$$

which has a value between 1 and 2 : $Q$ is $1-1.5$ for liquid and 1.5-2 for ice. If the cloud phase costs for liquid and ice phase assumptions have similar values, then $Q$ is nearly 1.5 , which means that cloud phase determination is ambiguous.

\section{Assumptions and prior information}

As shown by Cooper et al. (2003) and Garrett et al. (2009), explicit representation of cloud top and base boundaries is important in the TIR cloud retrieval. In this study, the cloud base pressure is parameterized using an empirical formula. Sassen and Comstock (2001) and Sassen et al. (2008) showed that the geometrical thickness of the cirrus with COT less than 3 is $1-3 \mathrm{~km}$ with a global mean of $2 \mathrm{~km}$ based on ground and spacebased lidar observations. Sassen and Comstock (2001) and Veglio and Maestri (2011) showed that an optically thicker cirrus cloud becomes geometrically thicker. In the present algorithm, the geometric thickness, $H(\mathrm{~m})$, is represented by a function of CWP, $W\left(\mathrm{~kg} \mathrm{~m}^{-2}\right)$,

$$
H=\left\{\begin{array}{ll}
B_{\text {liq }}+A_{\text {liq }} \sqrt{W / W_{\text {liq }}} & \text { for liquid cloud } \\
B_{\text {ice }}+A_{\text {ice }} \sqrt{W / W_{\text {ice }}} & \text { for ice cloud }
\end{array},\right.
$$

where

$$
\begin{aligned}
& B_{\text {liq }}=20 \mathrm{~m}, B_{\text {ice }}=20 \mathrm{~m}, \\
& A_{\text {liq }}=400 \mathrm{~m}, A_{\text {ice }}=2000 \mathrm{~m}, \\
& W_{\text {liq }}=0.06 \mathrm{~kg} \mathrm{~m}^{-2}, W_{\text {ice }}=0.02 \mathrm{~kg} \mathrm{~m}^{-2} .
\end{aligned}
$$

The cloud base pressure is determined from $H$ and atmospheric temperature and pressure profiles.

The prior information about the cloud properties and background surface temperature is given in Table 3, where $T_{\text {sfc }}^{\prime}$ is the sea or land surface temperature obtained from the MODIS level 3 product, $W$ is CWP, and $r_{\mathrm{e}}$ is CER. It is assumed that the surface temperature

\begin{tabular}{|c|c|c|c|c|}
\hline Variable & A priori & Standard deviation & Min. & Max. \\
\hline COT, liquid clouds & - & - & 0.25 & $30(8)^{a}$ \\
\hline COT, ice clouds & - & - & 0.04 & $30(8)$ \\
\hline$T_{\text {sfc }}(K)$, ocean & $T_{\text {sfc }}^{\prime}$ & 0.7 & $T_{\mathrm{sfc}}^{\prime}-2.1$ & $T_{\mathrm{sfc}}^{\prime}+2.1$ \\
\hline$T_{\text {sfc }}(K)$, land & $T_{\text {sfc }}^{\prime}$ & 3 & $T_{\text {sfc }}^{\prime}-9$ & $T_{\mathrm{sfc}}^{\prime}+9$ \\
\hline \multicolumn{5}{|c|}{ Liquid cloud properties } \\
\hline $\ln \left[W\left(\mathrm{~kg} / \mathrm{m}^{2}\right)\right]$ & $\ln 0.04$ & 4 & - & - \\
\hline $\ln \left[r_{\mathrm{e}}(\mu \mathrm{m})\right]$ & $\ln 10$ & 1.0 & $\ln 2$ & $\ln 30$ \\
\hline \multicolumn{5}{|l|}{ Ice cloud properties } \\
\hline $\ln \left[W\left(\mathrm{~kg} / \mathrm{m}^{2}\right)\right]$ & $\ln 0.02$ & 4 & - & - \\
\hline $\ln \left[r_{\mathrm{e}}(\mu \mathrm{m})\right]$ & $\ln 25$ & 1.0 & $\ln 3$ & $\ln 100$ \\
\hline
\end{tabular}
RMSEs are set to include the uncertainty from daily diurnal variations. The a priori probability distributions of CWP have large dispersions to under-constrain the
Table 3 A priori information and prescribed ranges of the elements of the solution vector

CWP retrieval. In contrast, the a priori CER has a relatively small standard deviation because CERs obtained from passive remote sensing are in limited ranges (Hong et al. 2007; Wang et al. 2016). $S_{\mathrm{a}}$ is an almost diagonal matrix, with weak correlation between the CWP and CER with a correlation coefficient of 0.25 . In the inversion, cloud properties are limited to prescribed ranges of realistic values. Lower and upper limits of COT are set because the TIR measurements lose sensitivity in cases with very small and large COTs.

Because the temperature ranges at which liquid and ice clouds exist are known a priori, the a priori and variance of CTP are determined by considering the vertical distribution of the air temperature profile. It is assumed that a liquid (ice) cloud is not present with CTT lower than $-40{ }^{\circ} \mathrm{C}$ (higher than $2{ }^{\circ} \mathrm{C}$ ). In addition, the a priori CTT $\left(T_{\mathrm{a}}\right)$ and CTP range are assumed as follows.

- For liquid clouds, $P_{\mathrm{flz}}<P_{\text {top }}<0.96 P_{\mathrm{sfc}}, T_{\mathrm{a}}=5^{\circ} \mathrm{C}$

- For ice clouds, $0.9 P_{\text {trp }}<P_{\text {top }}<P_{\text {mlt }}, T_{\mathrm{a}}=-55^{\circ} \mathrm{C}$

$P_{\text {frz }}$ and $P_{\text {mlt }}$ are pressures at an air temperature of -40 and $2{ }^{\circ} \mathrm{C}$, respectively, and $P_{\mathrm{tpp}}$ is a tropopause pressure. The standard deviation of the a priori CTP on a logarithmic scale, $\sigma_{\ln \beta}$ is determined to cover the CTP ranges as

$$
\sigma_{\ln P}=0.7 \times \max \left[\left|\ln \left(P_{a} / P_{\min }\right)\right|,\left|\ln \left(P_{a} / P_{\max }\right)\right|\right]
$$

where $P_{\mathrm{a}}$ is a priori CTP, and $P_{\min }$ and $P_{\max }$ are the lower and upper limits of CTP, respectively, determined as previously mentioned.

\section{Measurement and model errors}

Observations and models may have bias and noise-like error components arising from various error sources. Model errors include (1) error due to radiative transfer 
approximations, (2) errors from the representation of atmosphere with a finite number of atmospheric layers, (3) errors in the sea or land surface emissivity, (4) uncertainty in atmospheric temperature and gas concentration profiles, (5) error from assuming the cloud base pressure, (6) uncertainty of the ice habit model and particle size distribution, and (7) error from the vertical and horizontal heterogeneity of the clouds. Each error component may depend on the state of the atmosphere and the background surface, which make it complicated to quantify the error covariance matrix appropriately.

Simple assumptions can be made about several error components. The RMSE of sea surface temperature is assumed as $0.7 \mathrm{~K}$ in the inversion by considering daily and diurnal variations in sea surface temperature and possible differences between clear-sky and cloudy cases. According to the observations of Newman et al. (2005), the RMSE of sea surface emissivity due to the uncertainty of seawater optical constants is estimated to be approximately 0.001 at satellite zenith angles of less than $60^{\circ}$. Over land, the surface temperature and emissivity in cloudy cases are likely to differ significantly from those in clear-sky cases, although the magnitude is uncertain. The RMSE of land surface temperature is assumed as $3 \mathrm{~K}$ in this study, although precise quantification is required in the future. BFED land surface emissivity product (Seemann et al. 2008) is created by using the MODIS land surface emissivity product. The error covariance matrix of the land surface emissivity is constructed considering the MODIS product error and the BFED modeling error documented in the literature.

The measurement-model error covariance matrix is divided into two components, as

$$
S_{\mathrm{e}}=K_{\mathrm{b}} S_{\mathrm{b}} K_{\mathrm{b}}^{\mathrm{T}}+S_{\mathrm{e}, \mathrm{off}} .
$$

The first and second terms on the right-hand side are online and offline calculation terms, respectively. The online term is calculated from the error covariance matrix, $S_{\mathrm{b}}$, and the Jacobian matrix, $K_{\mathrm{b}}$, for the model parameters. $K_{\mathrm{b}}$ is calculated in the forward model. Model parameters included in the online calculation term are the background surface emissivity for each band and cloud base pressure. For the cloud base pressure error, the standard deviation of the logarithm of the cloud base pressure is assumed to be approximately proportional to the geometrical thickness of the cloud, which is approximately proportional to $\ln \left(P_{\text {bas }} / P_{\text {top }}\right)$, as

$$
\sigma=S_{\text {bas }} \ln \left(\frac{P_{\text {bas }}}{P_{\text {top }}}\right),
$$

where factor $S_{\text {bas }}$ is 0.2 . The offline calculation term is divided into three components as

$$
S_{\mathrm{e}, \mathrm{off}}=S_{\mathrm{e}, \mathrm{RTM}}+S_{\mathrm{e}, \mathrm{atm}}+S_{\mathrm{e}, \mathrm{noise}} .
$$

The right-hand side contains the errors from radiative transfer approximation, $S_{\mathrm{e}, \mathrm{RTM}}$, atmospheric profile uncertainty, $S_{\mathrm{e}, \mathrm{atm}}$, and measurement noise, $S_{\mathrm{e}, \text { noise. }}$ $S_{\mathrm{e}, \mathrm{RTM}}$ is small, as previously described.

To estimate several error components in the measurements and the model, BTs from daytime clear-sky pixel measurements over the ocean are compared with those from the model. Because the RMSE of sea surface temperature is as small as $0.7 \mathrm{~K}$, errors in atmospheric data and model approximations and assumptions are evaluated by the comparison. The clear-sky area is determined based on the cloud mask data in the MODIS Product (Ackerman et al. 1998). If an area about $30 \mathrm{~km}^{2}$ is composed of only the "confidently clear" pixels, then the center area of about $20 \mathrm{~km}^{2}$ is used for the model-measurement comparison. The covariance matrix of measurement noise, $S_{\mathrm{e}, \text { noise }}$, is estimated from the variance and covariance of measurement-model differences within a $20 \mathrm{~km}^{2}$ area. The maximum noise is $0.4 \mathrm{~K}$ at MODIS band 27, and the noise is less than $0.25 \mathrm{~K}$ in the window bands. Figure 2 shows comparisons of the clear-sky BTs. Each data point represents mean values over a $20 \mathrm{~km}^{2}$ segment. Water vapor absorption bands tend to exhibit larger differences between model and measurement as uncertainties in temperature and water vapor amount increase model errors. From this comparison, the systematic difference (bias) between the observations and model calculations is evaluated for each MODIS band, and then the biases are removed from the forward model used in the subsequent analyses.

The atmospheric profile error is estimated from the covariance matrix of measurement-model differences obtained in the oceanic clear-sky comparison. The vertical distribution of error patterns of temperature and water vapor, and ozone mixing ratios are determined by fitting the simulated error covariance matrix to the observations. The best estimate of the error covariance matrix is shown in Fig. 3 along with that obtained from observation. By using the estimated atmospheric profile errors, $S_{\text {e,atm }}$ for cloudy cases is evaluated by model simulations under a variety of atmospheric conditions. The error in cloudy cases strongly depends on CTT, because a major source of atmospheric profile error in cloudy cases is the error in the amount of water vapor above the cloud top. For lower CTTs, the amount of water vapor above the cloud top generally tends to be smaller in various atmospheric profiles. Thus, $S_{\mathrm{e}, \mathrm{atm}}$ for cloudy cases is tabulated in five CTT ranges from 200 to $300 \mathrm{~K}$ with an interval of $20 \mathrm{~K}$. The results for high and low CTTs are shown in Fig. 3. The error covariance matrix with high CTT is close to that for clear-sky cases. The 

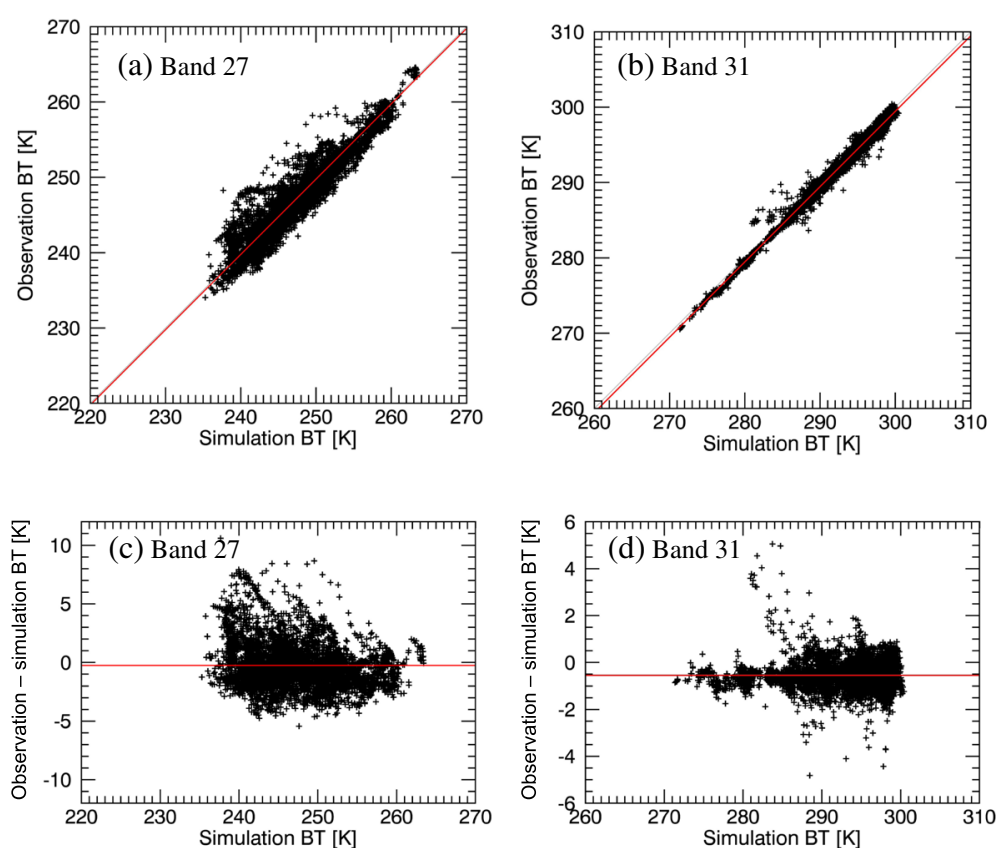

Fig. 2 Comparison of observed and simulated BTs for clear-sky pixels over the ocean. Results are shown for MODIS band 27 (water vapor absorption band) and band 31 (window band). Scatterplots of observed BTs $(\mathbf{a}, \mathbf{b})$ and differences in the observation from the simulation (c, d). Red lines in $\mathbf{a}$ and b denote fit lines with a slope constrained to be 1. Red lines in $\mathbf{c}$ and $\mathbf{d}$ denote biases. Each data point represents mean values over a $20 \mathrm{~km}^{2}$ segment

errors decrease at the water vapor absorption bands for lower CTT.

Because not all error sources are included in Eq. (13), initial tests show that the model does not fit the measurements well if Eq. (13) is used directly in the cloud property inversion. The uncertainty due to the horizontal and vertical heterogeneity in clouds and the uncertainty in the optical properties of ice particles from the ice habit model are not included in Eq. (13). These uncertainties are difficult to quantify; however, based on by trial and error, we artificially set the diagonal elements of the error covariance matrix obtained from Eq. (13) as $20 \%$ larger.

\section{Results and discussion}

\section{Retrieval error evaluation by simulations}

The errors and performance of cloud retrieval are tested by retrieval simulations. Measurement signals with errors are simulated by the forward model calculations for perturbed atmospheric and surface states with random noise that obey the error covariance matrices assumed above. Retrieval errors are evaluated by comparing the retrieved cloud properties from the noisesuperimposed measurement signals with the initial values. This methodology is identical to that used by Iwabuchi et al. (2014). For each state, a series of 1000 retrieval simulations are performed to evaluate the mean bias error and the RMSE. The satellite viewing (a) Observed (clear-sky)

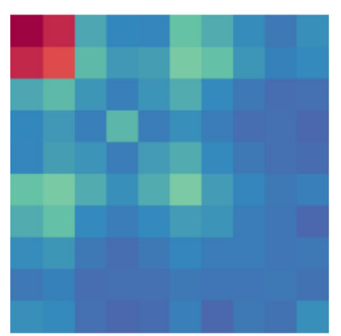

(c) Cloudy $(\mathrm{CTT}=280-300 \mathrm{~K})$

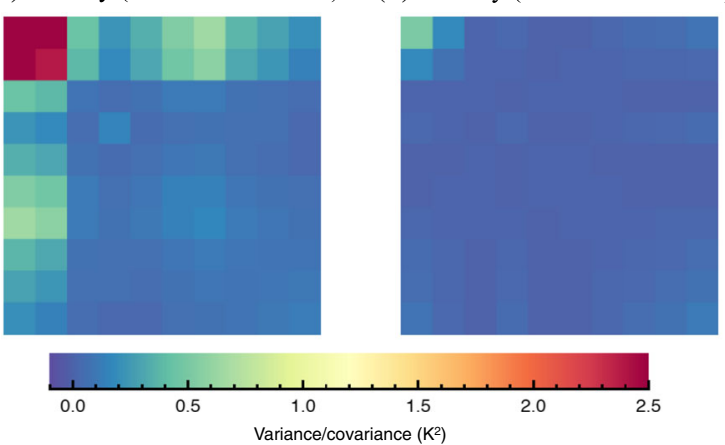

Fig. 3 Model error covariance matrices for atmospheric profile errors. a Estimation from comparison of clear-sky observations over the ocean to model calculations. b, c, d Estimations from Monte Carlo simulation of estimated errors in atmospheric profiles, for $\mathbf{b}$ clear sky, c cloudy sky with CTT of 280-300 K, and $\mathbf{d}$ cloudy sky with CTT of 280-300 K. Each panel shows an image of error covariance matrix. The row and columns denote ten MODIS bands 
zenith angle ranges from $0^{\circ}$ to $60^{\circ}$, and a tropical atmosphere is assumed with a sea surface temperature of $300 \mathrm{~K}$.

Figure 4 shows results for ice clouds with $\mathrm{CTT}=$ $221 \mathrm{~K}$. The retrieval bias and RMSE, correct cloud phase discrimination rate, and DOFS are shown by color scales as functions of initially assumed values (truth values in this test) of COT and CER. The rate of the optimal cloud retrievals for all trials is also computed for each cloud state. The retrieval errors presented are evaluated only for optimal retrievals with correct cloud phase identification. The estimation of CTP is accurate with a small bias of within $\pm 10 \%$ for almost all cloud states tested here. CTP RMSE is less than $20 \%$ for optically thick clouds with COT of 0.3 or more. When the initial COT is $0.1-$ 10 and CER is $3-60 \mu \mathrm{m}$, the CER and COT retrieval biases are generally less than $15 \%$, RMSE is less than $30 \%$, and DOFS is close to 3 . For very thin and very thick clouds, the sensitivity of the forward model to CER is low, which explains the CER retrievals close to the a priori values and the low DOFS. Optimal cloud retrievals are obtained for $100 \%$ of clouds with COT of 0.1. Optically thinner clouds are not retrieved because they are excluded in the retrieval algorithm as clear sky. With the

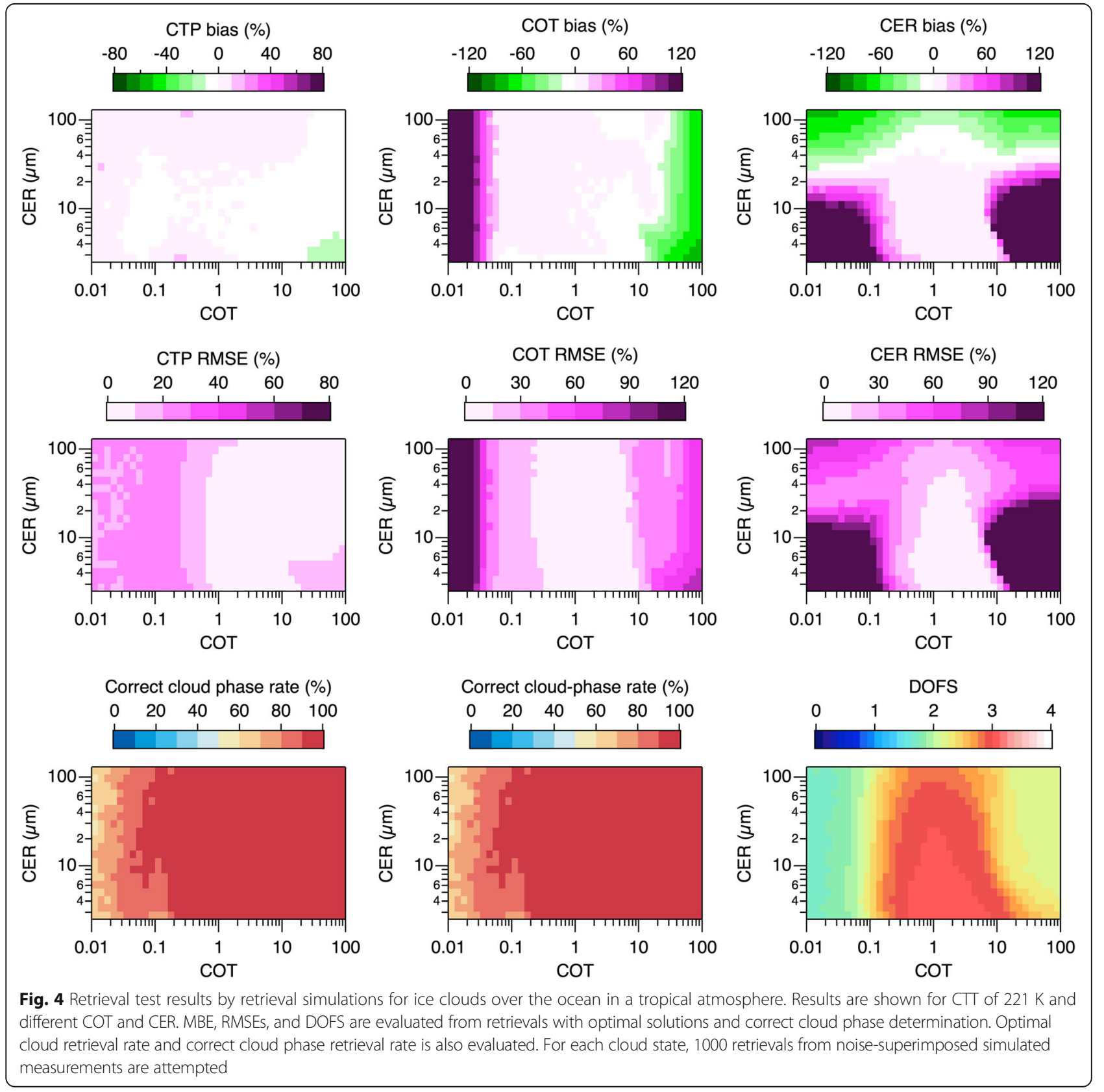


exception of cases with very optically thin clouds, cloud phase determination is correct with a correct identification rate of about $100 \%$.

Figure 5 shows the results for liquid clouds with CTT $=277 \mathrm{~K}$. Because the CTT is closer to the background surface temperature than for ice clouds, the retrieval performance for liquid cloud is worse than for ice clouds, resulting in lower DOFS. The CTP bias and RMSE are very small over a wide range of COT and CER, which is better than for ice clouds. This is mainly because a liquid cloud is geometrically thinner than an ice cloud. Use of a weakly absorbing $\mathrm{CO}_{2}$ band (MODIS band 33) might improve the estimation of the top of low clouds. Both CER and COT bias are within $\pm 30 \%$ when the COT is $0.3-20$ and CER is $4-20 \mu \mathrm{m}$. The percentage of correct cloud phase identification is about $100 \%$ in most cases shown here. When both the COT and CER are small, cloud phase identification is not correct with a score of about $50 \%$. This is because COT is limited to be more than 0.25 for liquid clouds.

Retrieval performance is tested at various CTTs. The initial assumptions, as the truth in this test, about cloud phase are as follows. There is exclusively an ice cloud for $\mathrm{CTT} \leq-38^{\circ} \mathrm{C}$, exclusively a liquid cloud for CTT $\geq$ $0{ }^{\circ} \mathrm{C}$, and the ice and liquid cloud fractions vary linearly with CTT between -38 and $0{ }^{\circ} \mathrm{C}$. CERs are assumed to

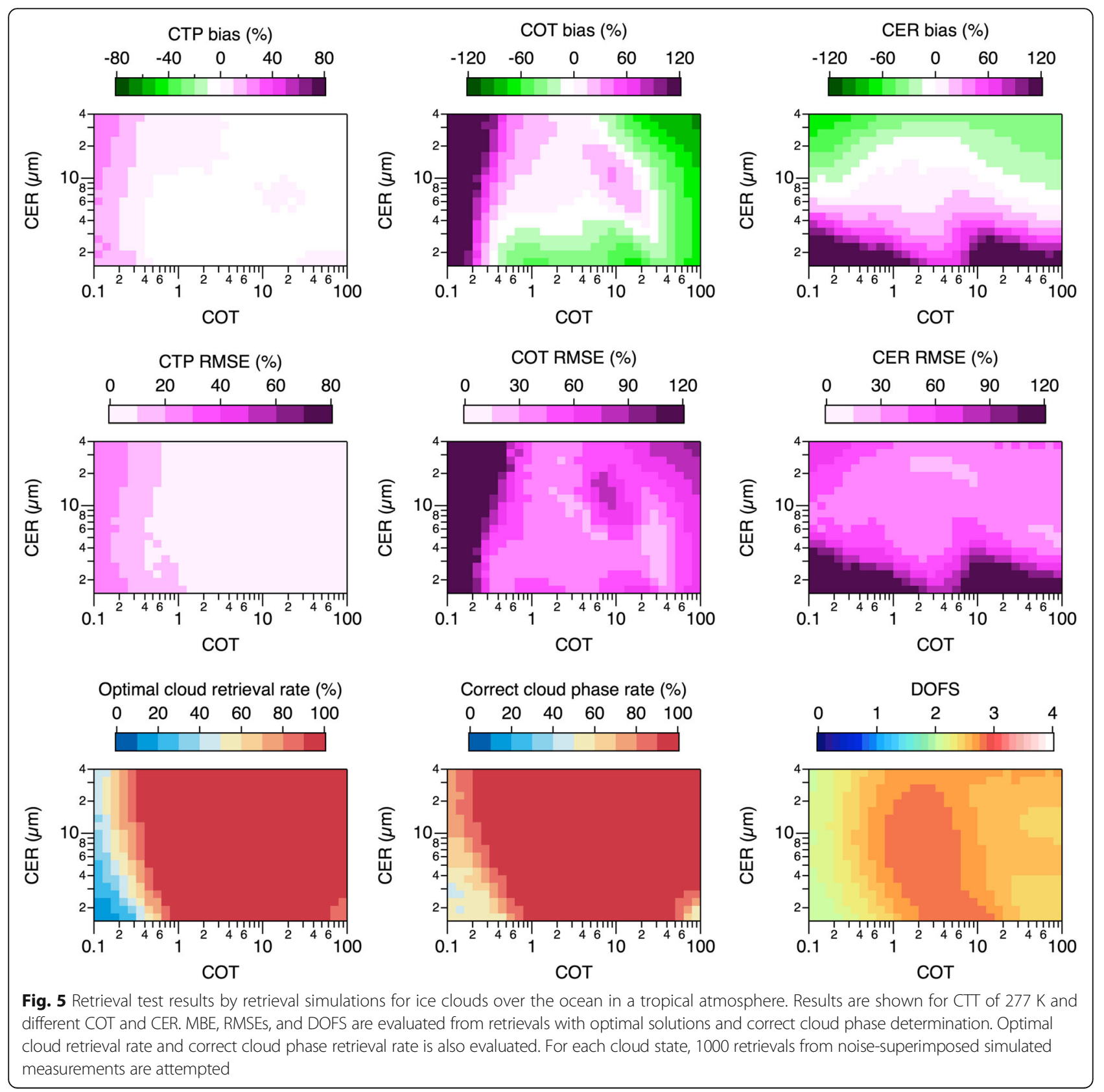


be typical values of $13 \mu \mathrm{m}$ for liquid clouds and $32 \mu \mathrm{m}$ for ice clouds. Figure 6 shows the test results. The optimal cloud retrieval rate is approximately $100 \%$ for clouds that are optically thick enough. Very optically thin clouds are not retrieved because they are identified as clear sky in the retrieval algorithm. Cloud phase discrimination is accurate for CTT lower than $-38{ }^{\circ} \mathrm{C}$ or higher than $0{ }^{\circ} \mathrm{C}$, except for very optically thin cases. Cloud phase determination is difficult when CTT is between the two critical temperatures, particularly for COT of less than 0.5. CTP of optically thin (COT <0.3) clouds also has a problem with biases. Low sensitivity to CTP means that CTP retrievals tend to be close to the a priori values. The poor estimation accuracy of the CTP is observed for CTT around 200 and $265 \mathrm{~K}$. However, the CTP can be retrieved accurately for optically thick clouds for any CTTs. The CTP bias is less than $10 \%$ for
COT $>0.3$, and the CTP RMSE is less than about $10 \%$ for COT $>0.5$. For the retrieval error of COT, the bias is less than $15 \%$, and the RMSE is less than $30 \%$ for high clouds with $\mathrm{COT}=0.1-10$. The COT retrieval error generally increases with increasing CTT. However, CER retrieval shows good performance over wide ranges of CTT and COT in this test, where CER truths are assumed to be close to the a priori values.

It would be desirable to clarify the benefits of using ten TIR bands to retrieve cloud macrophysical and microphysical properties simultaneously. In the $\mathrm{CO}_{2}$ slicing technique for CTP retrieval, cloud effective temperature is estimated assuming that the cloud is isothermal and the cloud emissivities in the two neighboring bands are identical. Cloud emissivities in the split window bands can be obtained by using this cloud temperature estimate. Heidinger et al. (2015) presented

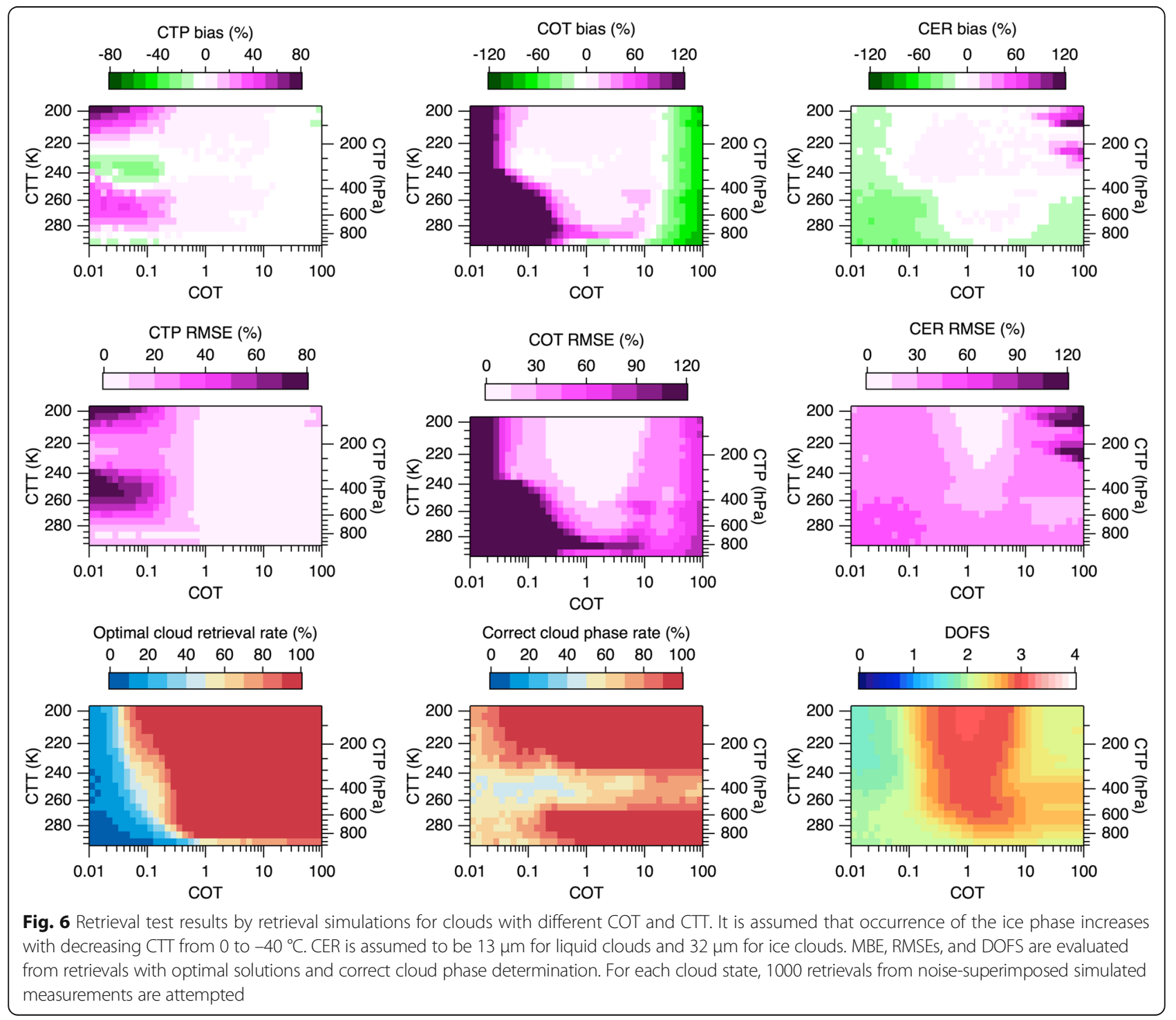


a simple, efficient two-stage method for retrieving COT and CER from the cloud emissivities in the split window. First, the macrophysical properties (CTP/CTH/ CTT) are retrieved, followed by the optical and microphysical properties. Iwabuchi et al. (2014) also used the CTT obtained from the $\mathrm{CO}_{2}$ slicing technique to help estimate the optical and microphysical properties from the split window bands of MODIS. In the present study, we test a surrogate method for CTP retrieval, instead of the $\mathrm{CO}_{2}$ slicing technique itself. MODIS bands 35 and 36 are used to retrieve CTP in the optimal estimation framework, with CER strictly constrained at the a priori value for ice clouds. The two bands are sensitive to the upper troposphere. In the MODIS cloud product, CTPs of most high clouds in the tropics are retrieved by using those two bands. The fixed CER assumption is reflected in the fixed spectral dependence of the optical properties of the ice particles, which is a better assumption than identical cloud emissivities at the two bands. Figure 7 shows the CTP retrieval errors for ice clouds with a CER of the a priori value $(25 \mu \mathrm{m})$. The two-band retrieval is compared with the ten-band retrieval with the same assumptions about the measurement and model errors. The simultaneous retrievals from using all ten bands outperform those based on using only the

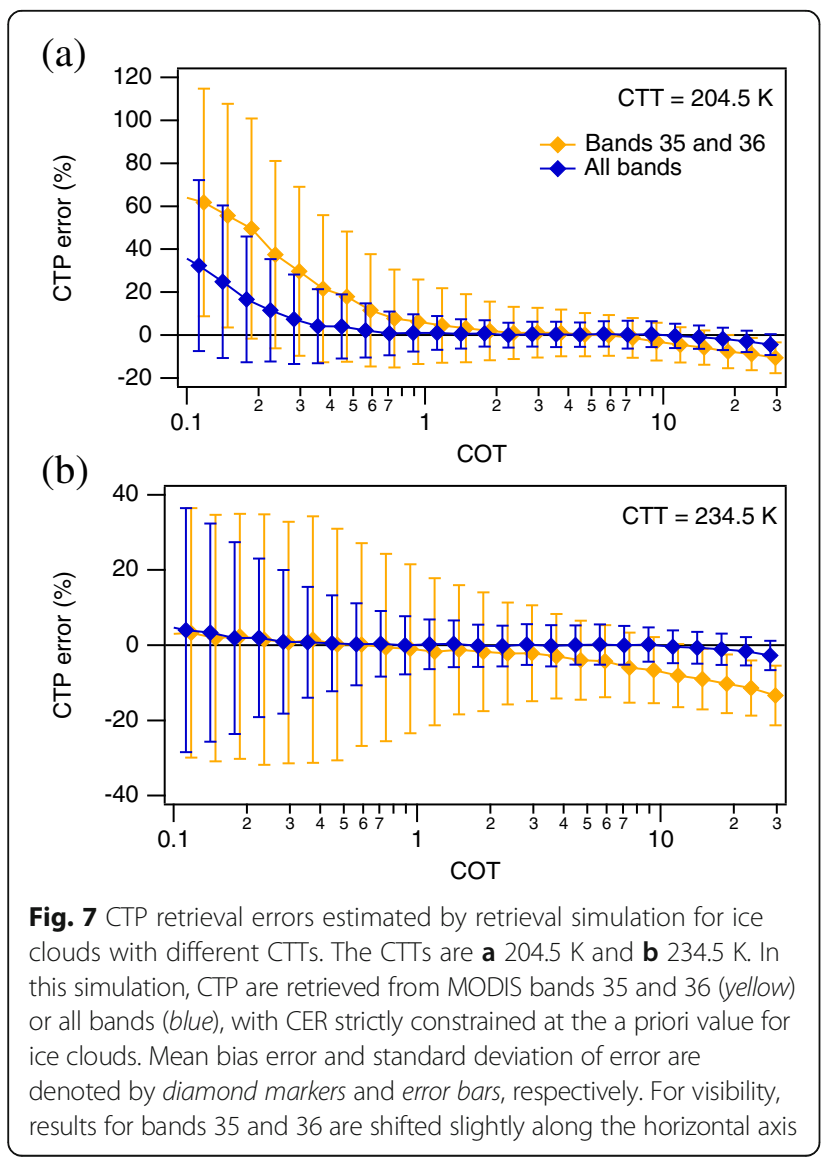

two $\mathrm{CO}_{2}$ bands, and the ten-band retrieval produces more certain estimates of CTP. If the assumed cloud temperature is highly uncertain in the second stage of retrieval of COT and CER, it is likely that the COT and CER estimates will be more erroneous. The simultaneous retrieval of macrophysical and microphysical properties can provide better consistency between the physics model and measurements for all bands.

\section{Application to tropical cloud systems}

As an initial test, the results obtained from the present retrieval algorithm in ICAS are compared with the MODIS C6 cloud products with a $1 \mathrm{~km}$ resolution. The MODIS granule in this case is acquired on April 1, 2007, at 3:55 UTC, which is the same as the case in Iwabuchi et al. (2014). The region is located in the ocean to the north of New Guinea. An area of about $200 \times 1200 \mathrm{~km}$ is selected to illustrate the comparison results, covering the CloudSat/CALIPSO ground track (Fig. 8). The CTH obtained from ICAS is compared with the CloudSat/ CALIPSO cloud mask product developed by Kyushu University (Hagihara et al. 2010). Because CloudSat/ CALIPSO observes the Earth in a nadir view, a parallax correction is applied to the ICAS retrieval to compare the datasets coherently. Furthermore, the parallaxcorrected ICAS retrieval is regridded into the CloudSat/ CALIPSO track by using nearest neighbor interpolation. The evaluated pixels are only pixels with optimal retrieval. In the region of interest, there are about 1868 collocated pixels between ICAS (with optimal retrieval) and the radar-lidar product. More than $90 \%$ of the pixels are detected as cloudy pixels by both products, whereas about $2 \%$ are detected as clear-sky pixels. ICAS incorrectly assigns about $1.5 \%$ of pixels as cloudy and misses about $0.5 \%$ of cloudy pixels in the radar-lidar product, although collocation is not certain owing to the parallax.

Figure 8 shows that the radar-lidar product detects many pixels with a high cloud top. The upper clouds cover wide areas, and parts of the left and right sides of the figures are covered with thick clouds. Middle-level clouds are present in the middle of the figures. The MERRA atmospheric profile shows that the CTT of the middle cloud is about $-20{ }^{\circ} \mathrm{C}$. The upper part of the high clouds probably consists of small ice particles and it can be detected only by lidar (green). The $\mathrm{CTH}$ obtained from ICAS tends to be lower than that of the radar-lidar product and close to the cloud top detected by cloud radar (blue and yellow). The top height of ICAS varies from 5 to $17 \mathrm{~km}$, whereas the radar-lidar product has a more uniform top height with an altitude of around $15 \mathrm{~km}$. Similar to the ICAS cloud top, the cloud top detected by radar is more variable than the cloud top detected by lidar. This is an expected limitation of ICAS 
(a) $\mathrm{RGB}=6 / 2 / 31$

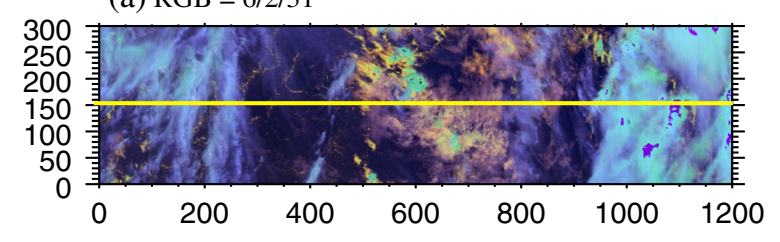

(b) $\mathrm{RGB}=29-31 / 32 / 31$
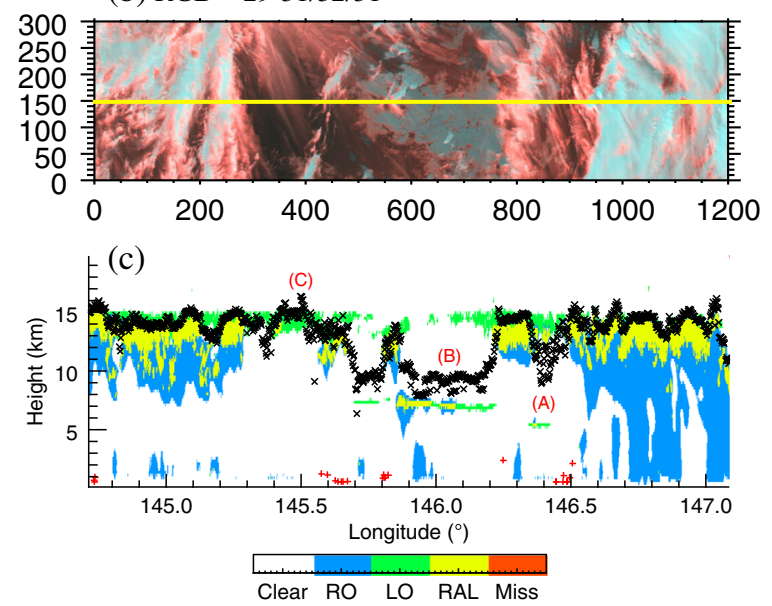

Fig. 8 A test case of tropical cloud systems over the ocean north of New Guinea. The MODIS granule is taken at 3:55-4:00 UTC on April 1, 2007. $\mathbf{a}$, b False color image with band combinations of MODIS bands. a Reflectances in bands 6, 2, and 31 and $\mathbf{b}$ BTD between bands 29 and 31 and BTs of 32 and 31 for the red, green, and blue channels. Yellow lines in $\mathbf{a}$ and $\mathbf{b}$ denote the ground track of CloudSat and CALIPSO satellite. c Comparison of retrieved CTHs with cloud mask data obtained from CloudSat radar and CALIPSO lidar measurements. Blue denotes clouds detected by radar only (RO), green by lidar only $(\mathrm{LO})$, yellow by both radar and lidar (RAL), and orange denotes missing data (Miss). The scattered crosses show the location of the ICAS cloud top at the respective longitude, where black crosses represent cloud top of the first layer and red crosses represent cloud top of the second layer

because previous studies have shown that IR measurements are not sensitive to very optically thin clouds, which can be sensed only by lidar and not by radar (Watts et al. 2011). ICAS detects more pixels with a cloud top above $15 \mathrm{~km}$ compared with radar-lidar products. Some pixels correspond to CTHs that are higher than the lidar measurements (around region $\mathrm{C}$ ). This is probably an erroneous retrieval because the ICAS results are influenced primarily by the uncertainty of the atmospheric profile, and possibly by the ice habit assumption and vertical inhomogeneity within the cloud, yielding an ICAS cloud top near the tropopause that is too high compared with the lidar measurement. Red crosses in Fig. 8c denote the cloud top of the lower cloud of the double-layer cloud retrieval in ICAS. Several parts of the second layer top in ICAS match the cloud top of the third cloud layer in the radar-lidar profile, although there are parts that deviate greatly. The cloud tops of the upper cloud layer in double- layer cases are well estimated, similar to single-layer cloud cases. ICAS misses most multilayer clouds at longitudes of $146.35^{\circ}-146.45^{\circ}$ (region A), where the upper first and second cloud layers are detected only by lidar. ICAS wrongly identified these pixels as single-layer cloud and retrieved CTHs between the first and second cloud layers. A similar problem occurs at longitudes of $146.1^{\circ}-146.2^{\circ}$ (region B). In these cases, the uppermost cloud is too optically thin, and ICAS cannot identify the upper cloud in a multilayer cloud system, probably because the retrieval with the single-layer cloud assumption has an optimal solution with clouds at the wrong height. These results suggest that the algorithm requires re-examination and improvement.

Figure 9 shows a comparison of the cloud properties in ICAS and C6. In C6, the VIS/SWIR method is used for cloud optical and microphysical properties (COT and $\mathrm{CER}$ ), and the $\mathrm{CO}_{2}$ slicing method and the IR window method are used to estimate the cloud top in C6. Two methods are used for cloud thermodynamic phase determination in the MODIS $1 \mathrm{~km}$ products. One is a method based on the BT and BTD in the TIR bands supplemented by using the cloud emissivity ratios (TIR method; Baum et al. 2012). The other is a method used in the retrieval of daytime optical properties of clouds (shortwave algorithm; Marchant et al. 2016), in which cloud phase is determined from "votes" from several tests based on the BTs of the TIR window bands, CER values determined from different combinations of multiple VIS and SWIR bands, CTT, and the water vapor absorption band at $1.38 \mu \mathrm{m}$. There is a high correlation between COTs in ICAS and C6, although the COT in ICAS tends to be smaller and limited to less than 20 . ICAS works well for retrieval of thin clouds. In C6, COT (CER) retrieval is not available for thin clouds with COT of less than about 0.5 (Eq. (1)). The retrieval in ICAS is available for many pixels of optically thin, high clouds. As shown in the previous subsection, CER of optically thick clouds has a large uncertainty in ICAS because of low sensitivity. In the optically thin parts at the edges of the upper clouds, the $\mathrm{CTH}$ in $\mathrm{C} 6$ is low, whereas ICAS $\mathrm{CTH}$ has high values. In the $\mathrm{CO}_{2}$ slicing method, C6 and ICAS agree well. In the IR window method, C6 shows low clouds with CTH of $0-3 \mathrm{~km}$, whereas the CTH is $10-15 \mathrm{~km}$ in ICAS, resulting in significant differences as large as $10 \mathrm{~km}$ or more. ICAS retrieval has more ice cloud pixels (Fig. 9i-k), particularly at optically thin edges of high clouds. Over the central area of the images, thin upper layer clouds overlap over the middle-level cloud, as seen in the radarlidar profile. In these areas, many pixels are determined as ice phases in ICAS, whereas CTHs are in the middle of the thin upper cloud and middle cloud. The shortwave algorithm in C6 shows a liquid phase for these 
(a) ICAS CTH

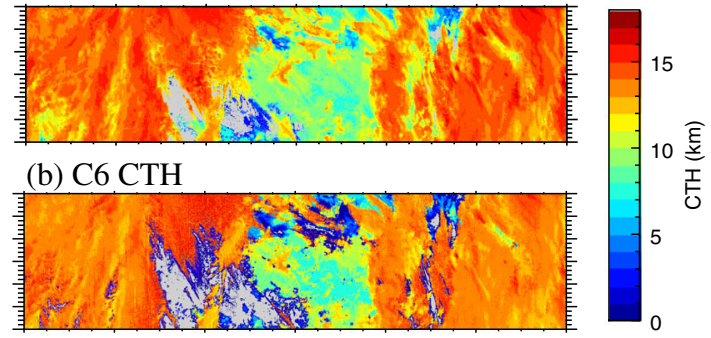

(d) ICAS COT

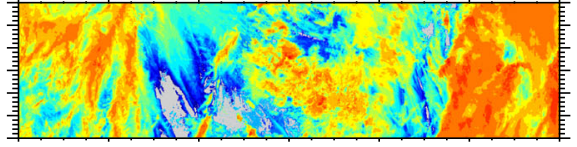

(e) C6 COT

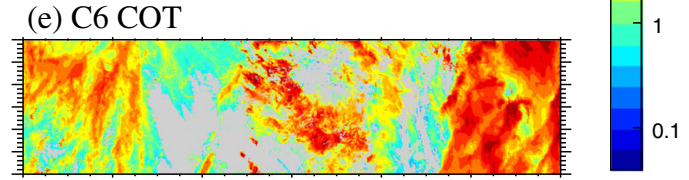

(h) ICAS cloud phase

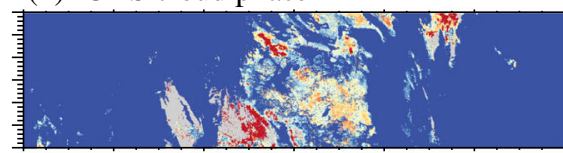

(i) ICAS cloud phase

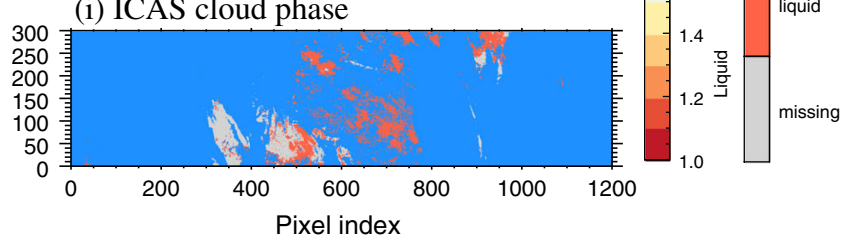

(c) C6 cloud top method

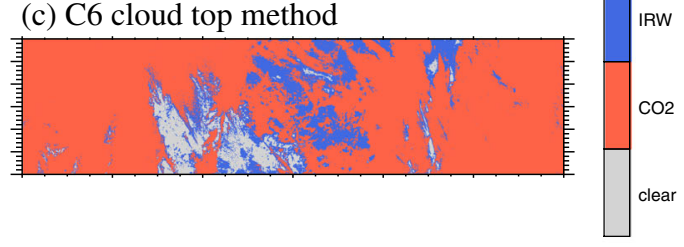

(f) ICAS CER

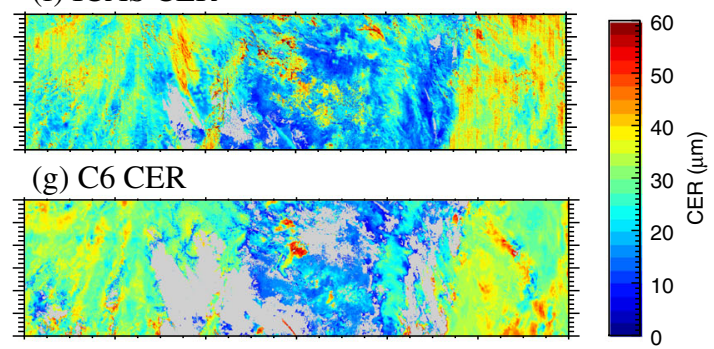

(j) C6 cloud phase (SW)

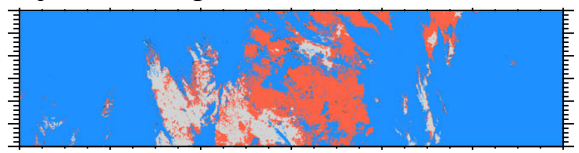

(k) C6 cloud phase (TIR)

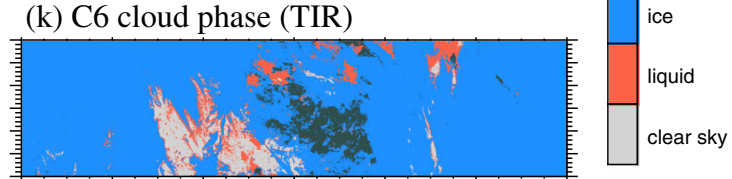

Fig. 9 Comparison of retrieved cloud properties between ICAS and MODIS products. CTH in a ICAS and b MODIS. c CTH method used in the MODIS product, showing pixels for the IR window and $\mathrm{CO}_{2}$ slicing methods and clear-sky pixels. COT in $\mathbf{d} I C A S$ and $\mathbf{e}$ MODIS. CER in $\mathbf{f} I C A S$ and g MODIS. Cloud thermodynamic phase estimated in ICAS. $\mathbf{h}$ The phase index defined in Eq. (10), and $\mathbf{i}$ binary results for the cloud phase. Ice/liquid binary results are based on the original cloud phase index data that has continuous values from 1 to 2 . Cloud thermodynamic phase estimated in the MODIS product: $\mathbf{j}$ shortwave (SW) algorithm and $\mathbf{k}$ TIR algorithm. Gray pixels in $\mathbf{k}$ represent the mixed phase

pixels, and the phase is undetermined in the TIR method in C6, indicating difficulty in determining unique cloud phases in multilayer cloud systems.

Statistical comparisons for the collocated pixels are made for a full granule that covers a $2000 \mathrm{~km}^{2}$ region. Figure 10 shows the CTH comparison between ICAS and C6. In $\mathrm{C} 6, \mathrm{CO}_{2}$ slicing is applied to the high clouds, and the $\mathrm{CTH}$ retrieval agrees well with the $\mathrm{CTH}$ in ICAS. In the optically thin ice clouds, $\mathrm{CTH}$ in $\mathrm{C} 6$ tends to be higher than the ICAS estimates (Fig. 10c). If the IR window method is used in C6, the pixels are covered by upper clouds in ICAS, whereas they are covered by low clouds in C6. When the comparison is limited to ice cloud retrieval in ICAS and IR window retrieval in C6, the ICAS-C6 difference in $\mathrm{CTH}$ tends to increase with decreasing COT. As seen in the spatial distribution, the optically thin parts at the edges of upper clouds are treated as lower clouds in C6. These results suggest that ICAS can capture the CTH of optically thin upper layer clouds well.

Figure 11 shows results for the COT and CER for ice clouds. COT shows good agreement when the COT is less than about 6 . For thick clouds, TIR measurements lose their sensitivity to the lower part of cloud systems, whereas the visible reflectance is sensitive to the total column COT. Many pixels with multilayer clouds are probably included in the results presented here. The COT from the TIR measurements should be considered as the COT of upper clouds in multilayer cloud systems. This explains why the C6 COT is often larger than ICAS COT, particularly when COT is larger than about 6 . In contrast, CERs in ICAS and C6 exhibit significant dispersion, showing a weak correlation with a correlation coefficient of 0.24 . The correlation is higher with a 

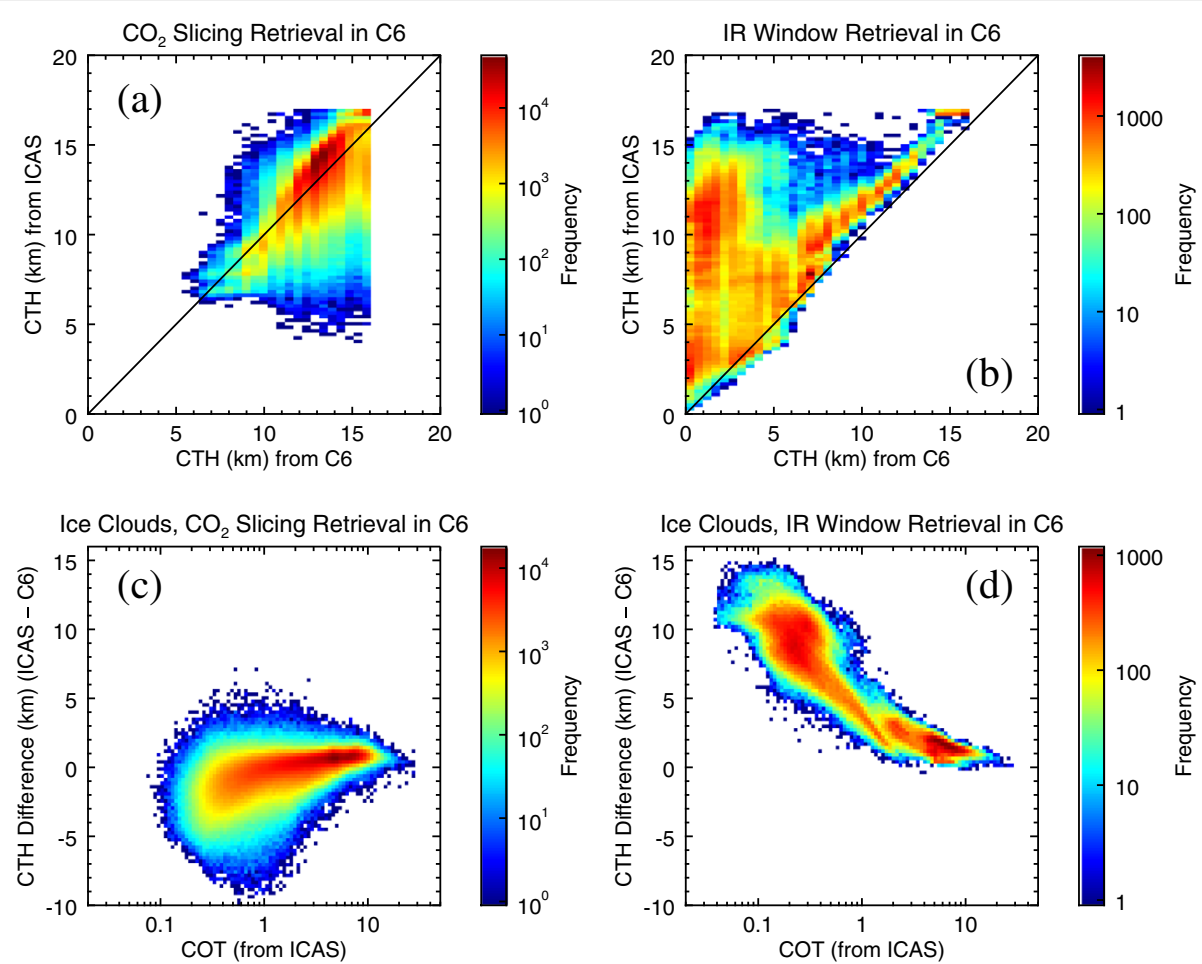

Fig. 10 Comparison of CTHs obtained from ICAS and the MODIS product. The occurrence frequency distributions are shown. Results are shown for pixels retrieved by the $\mathbf{a} \mathrm{CO}_{2}$ slicing method and $\mathbf{b} I \mathrm{R}$ window method in the MODIS product. CTH differences plotted against COT for ice clouds in ICAS retrieval for the $\mathbf{c} \mathrm{CO}_{2}$ slicing method and $\mathbf{d}$ IR window method in the MODIS product

coefficient of 0.31 for comparing ice clouds with COTs in a range of $1-6$, where both TIR and VIS/SWIR algorithms have a high sensitivity to CER.

A simple comparison of the cloud thermodynamic phase on a pixel-by-pixel basis does not make sense because different products retrieve or assume different CTTs in the cloud phase determination. We also compare the temperature dependence of the ice/liquid phase occurrence fraction. Figure 12 shows the ice cloud fraction as function of CTT. ICAS and C6 ice results are plotted against CTT for the products. The ice fraction in
ICAS decreases from 1 to 0 over a temperature range of -40 to $-0{ }^{\circ} \mathrm{C}$. The ice fraction from the C6 TIR algorithm is similar to ICAS for CTTs lower than $-5{ }^{\circ} \mathrm{C}$. In the C6 TIR algorithm, there are ice phase pixels even with CTT above $0{ }^{\circ} \mathrm{C}$. However, it is important to check that the absolute number of such pixels is small because most pixels are covered by ice clouds in the results from all the algorithms. In contrast, for the shortwave algorithm (dotted line), the ice fraction is much lower than those in the ICAS and C6 TIR algorithms. The cloud phase in the shortwave algorithm is determined to
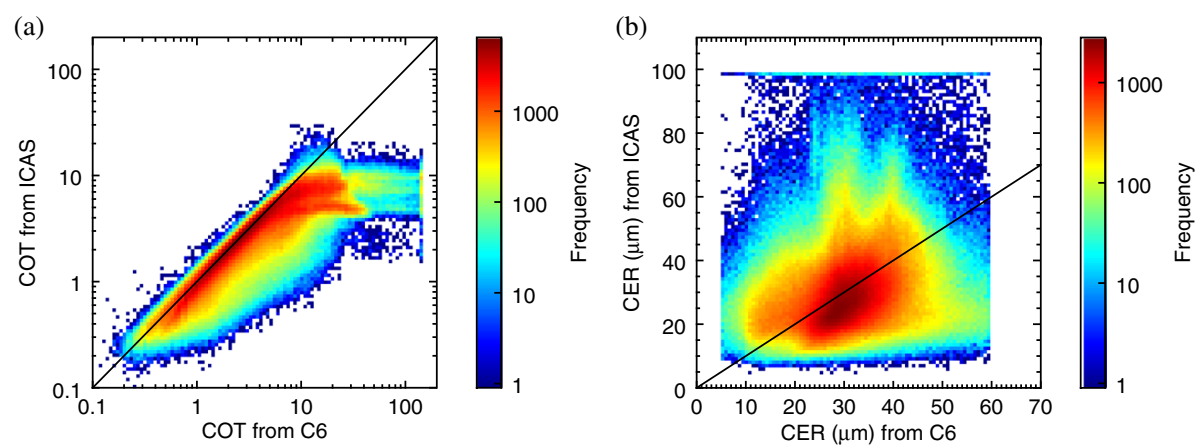

Fig. 11 Comparison of COTs and CERs obtained from ICAS and the MODIS product. Results for a COT and $\mathbf{b}$ CER of ice clouds, shown as the occurrence frequency distribution 


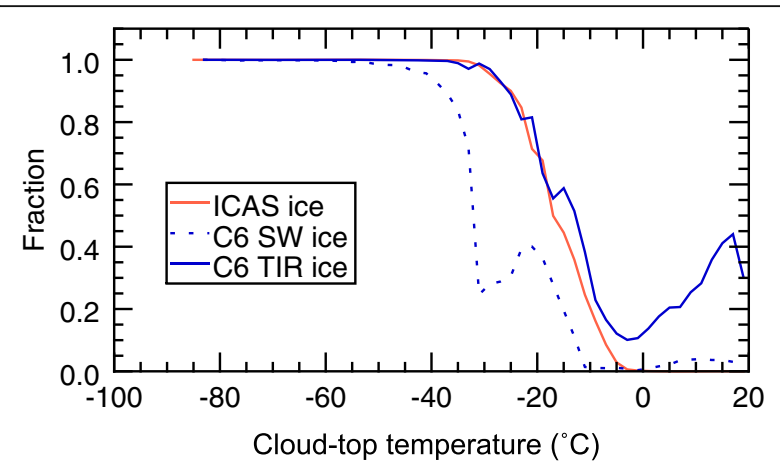

Fig. 12 Ice cloud occurrence fraction for ICAS and MODIS C6 SW and TIR algorithms. The ice fraction is shown as a function of CTT. The MODIS results are calculated from the numbers of pixels of ice, liquid, and mixed phase clouds, not including undetermined phase pixels

explain the VIS/SWIR reflectance measurements well. In multilayer cloud systems with optically thin ice clouds over optically thick liquid clouds, shortwave reflectances could be sensitive to the lower cloud. Thus, the cloud phase determination can differ from that from TIR measurement, which is sensitive to the upper cloud. In the C6 shortwave algorithm result, the ice fraction changes abruptly at a CTT of about $-33{ }^{\circ} \mathrm{C}(\sim 240 \mathrm{~K})$. According to Marchant et al. (2016), the CTT test uses a threshold at $240 \mathrm{~K}$ to "vote" for the ice clouds. This could result in the discontinuity of the ice fraction. As shown previously, cloud phase inference in ICAS is based on the consistency between the model and measurements under the constraints given by a priori knowledge about the relationship between CTT and the phase, relying on BTDs in the split window with large weights. Thus, the cloud phase determination in ICAS is constrained strongly by the cloud phase dependence on the CTTs, which guarantees that ice clouds that are too warm and liquid clouds that are too cold are not retrieved. However, the strong constraint on the cloud phase is a limitation of our algorithm because a small amount of information about the cloud phase comes from measurements. Baum et al. (2012) showed that in their algorithm refinement for MODIS C6, using cloud emissivity ratios between the split window bands substantially improves the inference of the ice cloud phase, especially for optically thin ice clouds. In future work, cloud phase inference could be improved by using this index.

\section{Conclusions}

An optimal estimation-based cloud retrieval algorithm has been developed to estimate the optical and physical properties of clouds simultaneously from measurements of several TIR bands. A major source of modeling errors is uncertainties in atmospheric profiles, which are usually difficult to quantify. In this study, they are assessed by direct comparison of the clear-sky observations over the ocean with the model calculations. This type of model-measurement comparison is important for developing cloud retrieval algorithms. A feature of the present algorithm is that the COT and the $\mathrm{CTH}$ is retrieved well for optically thin clouds by simultaneously fitting the model to the measurement in multiple TIR bands. Although the cloud top inferred from TIR measurement fluctuates with the cloud top from the cloud radar profile, the topmost parts of clouds seen only in the lidar profile are not detected well by TIR measurements. Compared with MODIS C6 operational products, COT of less than 5 agrees well, although CER deviates greatly. CTH estimates agree well for optically thick clouds when the MODIS product is based on the $\mathrm{CO}_{2}$ slicing method, whereas there is significant disagreement in CTHs between the present study and C6 products for optically thin clouds at the cloud edges. In the present algorithm, the determination of the cloud thermodynamic phase is strongly constrained by a priori knowledge about cloud phase dependence on the CTTs. It guarantees that ice clouds that are too warm and water clouds that are too cold are not retrieved; however, more statistical verification of the temperature dependence should be performed by increasing the number of cases.

The present algorithm will be used in studies with observations from the Himawari- 8 satellite, a Japanese nextgeneration geostationary meteorological satellite, which has been operated by the Japan Meteorological Agency since 7 July 2015 and carries a visible-to-IR imager with greatly improved radiometric, spectral, spatial, and temporal resolution (Bessho et al. 2016). The development strategy used in this study will be used to create an algorithm for Himawari-8. The algorithm will have several modifications to accommodate the different spectral bands and will have improvements to the multilayer cloud retrieval and cloud phase discrimination. CALIPSO lidar measurements are suitable for retrieving optically thin cloud and reliable cloud phase discrimination $(\mathrm{Hu}$ et al. 2009). Using depolarization lidar comparison on a global scale, would help determine the performance of the TIRbased algorithm. In the future, further comparison of collocated data from different cloud products will be performed to characterize respective strengths and limitations of different methods.

\section{Abbreviations}

BFED: Baseline-fit emissivity database; BT: Brightness temperature; BTD: Brightness temperature difference; C6: Collection 6; CALIPSO: CloudAerosol Lidar and Infrared Pathfinder Satellite Observation; CER: Cloudparticle effective radius; CKD: Correlated k-distribution; COT: Cloud optical thickness; CTH: Cloud-top height; CTP: Cloud-top pressure; CTT: Cloud-top temperature; DOFS: Degree of freedom for signal; ICAS: Integrated Cloud Analysis System; MBE: Mean bias error; MODIS: Moderate resolution imaging spectroradiometer; RMSE: Root-mean-square error; SWIR: Shortwave infrared; TIR: Thermal infrared; VIS: Visible 


\section{Acknowledgements}

The authors are grateful to Prof. Hajime Okamoto of Kyushu University, Japan, for providing the cloud mask data made from CloudSat/CALIPSO data and Dr. Shuichiro Katagiri of Kyushu University, Japan, for the valuable comments during this study.

The MODIS data were obtained from the NASA websites.

\section{Funding}

This work was promoted and supported by Japan Society for the Promotion of Science (JSPS) KAKENHI Grant Number 25287117.

\section{Availability of data and materials}

Data will not be shared because the main results of this paper are development of cloud retrieval technique and described fully in this paper.

\section{Authors' contributions}

$\mathrm{HI}$ proposed the topic, conceived and designed the study, and conducted major parts of the study. M. Saito collaborated with the corresponding author in the development of the inversion module and carried out the evaluations of forward model and retrieval errors. YT collaborated with the corresponding author in the development and evaluation of the forward model and carried out the analysis using the MODIS data. NSP carried out the comparison analysis using CloudSat/CALIPSO product data. M. Sekiguchi developed the CKD model. All authors read and approved the final manuscript.

\section{Competing interests}

The authors declare that they have no competing interests.

\section{Author details}

${ }^{1}$ Center for Atmospheric and Oceanic Studies, Graduate School of Science, Tohoku University, 6-3 Aoba, Aramakiaza, Aoba-ku, Sendai, Miyagi 980-8578, Japan. ${ }^{2}$ The Graduate School of Marine Science and Technology, Tokyo University of Marine Science and Technology, 2-1-6 Etchujima, Koto-ku, Tokyo 135-8533, Japan.

Received: 29 May 2016 Accepted: 26 September 2016 Published online: 21 October 2016

\section{References}

Ackerman SA, Strabala KI, Menzel WP, Frey RA, Moeller CC, Gumley LE (1998) Discriminating clear sky from clouds with MODIS. J Geophys Res 103:32-141. doi:10.1029/1998JD200032

Akima H (1970) A new method of interpolation and smooth curve fitting based on local procedures. J ACM 17:589-602

Baran AJ (2009) A review of the light scattering properties of cirrus. J Quant Spectrosc Radiat Transfer 110:1239-1260

Baum BA, Yang P. Heymsfield AJ, Schmitt CG, Xie Y, Bansemer A, Hu YX, Zhang Z (2011) Improvements in shortwave bulk scattering and absorption models for the remote sensing of ice clouds. J Appl Meteorol Climatol 50:1037-1056

Baum BA, Menzel WP, Frey RA, Tobin DC, Holz RE, Ackerman SA, Heidinger AK, Yang P (2012) MODIS cloud-top property refinements for Collection 6. J Appl Meteorol Climatol 51:1145-1163. doi:10.1175/JAMC-D-11-0203.1

Bessho K, Date K, Hayashi M, Ikeda A, Imai T, Inoue H, Kumagai Y, Miyakawa T, Murata H, Ohno T, Okuyama A, Oyama R, Sasaki Y, Shimizu Y, Shimoji K, Sumida Y, Suzuki M, Taniguchi $H$, Tsuchiyama $H$, Uesawa D, Yokota $H$, Yoshida R (2016) An introduction to Himawari-8/9—Japan's new-generation geostationary meteorological satellites. J Meteorol Soc Japan 94:151-183. doi:10.2151/jmsj.2016-009

Brown OB, Minnet PJ, Evans R, Kearns E, Kipatrick K, Kumar A, Sikorski R, Zavody A (1999) MODIS infrared sea surface temperature algorithm. Algorithm theoretical basis document Version 2.0. Miami University. http://modis.gsfc. nasa.gov/data/atbd/atbd_mod25.pdf. Accessed 28 May 2016.

Cole BH, Yang P, Baum BA, Riedi J, Labonnote LC, Thieuleux F, Platnick S (2013) Comparison of PARASOL observations with polarized reflectances simulated using different ice habit mixtures. J Appl Meteorol Climatol 52:186-196

Cooper SJ, L'Ecuyer TS, Stephens GL (2003) The impact of explicit cloud boundary information on ice cloud microphysical property retrievals from infrared radiances. J Geophys Res 108:4107. doi:10.1029/2002JD002611

Cooper SJ, L'Ecuyer TS, Gabriel PK, Baran A, Stephens GL (2006) Objective assessment of the information content of visible and infrared radiance measurements for cloud microphysical property retrievals over the global oceans. Part 2: Ice clouds. J Appl Meteorol 45:42-62

Davis SM, Avallone ML, Kahn BH, Meyer KG, Baumgardner D (2009) Comparison of airborne in situ measurements and Moderate Resolution Imaging Spectroradiometer (MODIS) retrievals of cirrus cloud optical and microphysical properties during the Midlatitude Cirrus Experiment (MidCiX). J Geophys Res 114:D02203. doi:10.1029/2008JD010284

Downing H, Williams D (1975) Optical constants of water in the infrared. J Geophys Res 80:1656-1661

Friedman D (1969) Infrared characteristics of ocean water. Appl Opt 8:2073-2078

Garnier A, Pelon J, Dubuisson P, Faivre M, Chomette O, Pascal N, Kratz DP (2012) Retrieval of cloud properties using CALIPSO imaging infrared radiometer. Part I: Effective emissivity and optical depth J Appl Meteorol Climatol 51: 1407-1425. doi:10.1175/JAMC-D-11-0220.1

Garrett KJ, Yang P, Nasiri SL, Yost CR, Baum BA (2009) Influence of cloud-top height and geometric thickness on a MODIS infrared-based ice cloud retrieval. J Appl Meteorol Climatol 48:818-832

Giraud V, Buriez JC, Fouquart Y, Parol F, Seze G (1997) Large-scale analysis of cirrus clouds from AVHRR data: assessment of both a microphysical index and the cloud-top temperature. J Appl Meteorol 36:664-675

Hagihara Y, Okamoto H, Yoshida R (2010) Development of combined CloudSat/ CALIPSO cloud mask to show global cloud distribution. J Geophys Res 115: D00H33. doi:10.1029/2009JD012344

Hartmann DL, Ockert-Bell ME, Michelsen ML (1992) The effect of cloud type on earth's energy balance: global analysis. J Climate 5:1281-1304

Heidinger AK, Pavolonis MJ (2009) Gazing at cirrus clouds for 25 years through a split window. Part I: methodology. J Appl Meteorol Climatol 48:1100-1116

Heidinger AK, Li Y, Baum BA, Holz RE, Yang P (2015) Retrieval of cirrus cloud optical depth under day and night conditions from MODIS Collection 6 cloud property data. Remote Sens 7:7257-7271. doi:10.3390/rs70607257

Hong G, Yang P, Gao BC, Baum BA, Hu YX, King MD, Platnick S (2007) High cloud properties from three years of MODIS Terra and Aqua collection-4 data over the tropics. J Appl Meteorol Climatol 46:1840-1856

Hu Y, Winker D, Vaughan M, Lin B, Omar A, Trepte C, Flittner D, Yang P, Nasiri SL, Baum B, Sun W, Liu Z, Wang Z, Young S, Stamnes K, Huang J, Kuehn R, Holz $R$ (2009) CALIPSO/CALIOP cloud phase discrimination algorithm. J Atmos Ocean Technol 26:2293-2309

Inoue T (1985) On the temperature and effective emissivity determination of semi-transparent cirrus clouds by bi-spectral measurements in the $10 \mu \mathrm{m}$ window region. J Meteorol Soc Jpn 63:88-89

Iwabuchi H, Yamada S, Katagiri S, Yang P, Okamoto H (2014) Radiative and microphysical properties of cirrus cloud inferred from the infrared measurements made by the moderate resolution imaging spectroradiometer (MODIS). Part I: retrieval method. J Appl Meteorol Climatol 53:1297-1316. doi:10.1175/JAMC-D-13-0215.1

Li J, Huang J, Stamnes K, Wang T, Lv Q, Jin H (2015) A global survey of cloud overlap based on CALIPSO and CloudSat measurements. Atmos Chem Phys 15:519-536. doi:10.5194/acp-15-519-2015

Liu C, Yang P, Minnis P, Loeb NG, Kato S, Heymsfield AJ, Schmitt CG (2014) A two-habit model for the microphysical and optical properties of ice clouds. Atmos Chem Phys 14:13719-13737. doi:10.5194/acp-14-13719-2014

Marchant B, Platnick S, Meyer K, Arnold GT, Riedi J (2016) MODIS Collection 6 shortwave-derived cloud phase classification algorithm and comparisons with CALIOP. Atmos Meas Tech 9:1587-1599. doi:10.5194/amt-9-1587-2016

Masuda K (2012) Influence of wind direction on the infrared sea surface emissivity model including multiple reflection effect. Pap Meteorol Geophys 63:1-13. doi:10.2467/mripapers.63.1

Menzel WP, Frey RA, Zhang H, Wylie DP, Moeller C, Holz RE, Maddux B, Baum BA, Strabala Kl, Gumley LE (2008) MODIS global cloud-top pressure and amount estimation: algorithm description and results. J Appl Meteorol Climatol 47: 1175-1198. doi:10.1175/2007JAMC1705.1

Mlawer EJ, Payne VH, Moncet JL, Delamere JS, Alvarado MJ, Tobin DD (2012) Development and recent evaluation of the MT_CKD model of continuum absorption. Phil Trans R Soc A 370:1-37. doi:10.1098/rsta.2011.0295

Nakajima T, King MD (1990) Determination of the optical thickness and effective particle radius of clouds from reflected solar radiation measurements. Part l: theory. J Atmos Sci 47:1878-1893

Nakajima T, Tsukamoto M, Tsushima Y, Numaguti A, Kimura T (2000) Modeling of the radiative process in an atmospheric general circulation model. Appl Opt 39:4869-4878 
Newman SM, Smith JA, Glew MD, Rogers SM, Taylor JP (2005) Temperature and salinity dependence of sea surface emissivity in the thermal infrared. Q J R Meteorol Soc 610:2539-2557. doi:10.1256/qj.04.150

Parol F, Buriez JC, Brogniez G, Fouquart Y (1991) Information content of AVHRR channels 4 and 5 with respect to the effective radius of cirrus cloud particles. J Appl Meteorol 30:973-984

Platnick S, King MD, Ackerman SA, Menzel WP, Baum BA, Riedi JC, Frey RA (2003) The MODIS cloud products: algorithms and examples from Terra. IEEE Trans Geosci Remote Sens 41:459-473. doi:10.1109/TGRS.2002.808301

Poulsen CA, Siddans R, Thomas GE, Sayer AM, Grainger RG, Campmany E, Dean SM, Arnold C, Watts PD (2012) Cloud retrievals from satellite data using optimal estimation: evaluation and application to ATSR. Atmos Meas Tech 5:1889-1910

Ramanathan V, Cess RD, Harrison EF, Minnis P, Barkstrom BR, Ahmad E, Hartmann DL (1989) Cloud-radiative forcing and climate: results from the earth radiation budget experiment. Science 243:57-63

Rienecker MM, Suarez MJ, Gelaro R, Toding R, Bacmeister J, Liu E, Bosilovich MG Schubert SD, Takacs L, Kim GK, Bloom S, Chen J, Collins D, Conaty A, Silva A, Gu W, Joiner J, Koster RD, Lucchesi R, Molod A, Owens T, Pawson S, Pegion P, Redder CR, Reichle R, Robertson FR, Ruddick AG, Sienkiewicz M, Woollen J (2011) MERRA: NASA's modern-era retrospective analysis for research and applications. J Climate 24:3624-3648. doi:10.1175/JCLI-D-11-00015.1

Rodgers CD (2000) Inverse methods for atmospheric sounding. World Scientific, Singapore

Rothman LS, Gordon IE, Babikov Y, Barbe A, Benner DC, Bernath PF, Birk M, Bizzocchi L, Boudon V, Brown LR, Camparque A, Chance K, Cohen EA, Coudert LH, Devi VM, Drouin BJ, Fayt A, Flaud JM, Gamache RR, Harrison JJ, Hartmann JM, Hill C, Hodges JT, Jacquemart D, Jolly A, Lamouroux J, Le Roy RJ, Li G, Long DA, Lyulin OM et al (2013) The HITRAN2012 molecular spectroscopic database. J Quant Spectrosc Radiat Transfer 130:4-50

Sassen K, Comstock JM (2001) A midlatitude cirrus cloud climatology from the facility for atmospheric remote sensing. Part III: radiative properties. J Atmos Sci 58:2113-2127

Sassen K, Wang Z, Liu D (2008) Global distribution of cirrus clouds from CloudSat/Cloud-Aerosol Lidar and Infrared Pathfinder Satellite Observations (CALIPSO) measurements. J Geophys Res 113:D00A12. doi:10.1029/ 2008JD009972

Seemann SW, Borbas EE, Knuteson RO, Stephenson GR, Huang HL (2008) Development of a global infrared land surface emissivity database for application to clear-sky sounding retrievals from multispectral satellite radiance measurements. J Appl Meteorol Climatol 47:108-123

Sekiguchi M, Nakajima T (2008) A k-distribution-based radiation code and its computational optimization for an atmospheric general circulation model. J Quant Spectrosc Radiat Transfer 109:2779-2793

Sourdeval O, Labonnote LC, Brogniez G, Jourdan O, Pelon J, Garnier A (2013) A variational approach for retrieving ice cloud properties from infrared measurements: application in the context of two IIR validation campaigns. Atmos Chem Phys 13:8229-8244. doi:10.5194/acp-13-8229-2013

Sourdeval O, Labonnote LC, Baran AJ, Brogniez G (2015) A methodology for simultaneous retrieval of ice and liquid water cloud properties. Part l: information content and case study. Q J R Meteorol Soc 141:870-882. doi:10.1002/qj.2405

Tsutsumi Y, Mori K, Hirahara T, Ikegami M, Conway TJ (2009) Technical report of global analysis method for major greenhouse gases by the World Data Center for Greenhouse Gases. GAW Report No. 184 (WMO/TD 1473), Geneva, pp 29

Veglio P, Maestri T (2011) Statistics of vertical backscatter profiles of cirrus clouds. Atmos Chem Phys 11:12925-12943. doi:10.5194/acp-11-12925-2011

Waliser DE, Li JLF, Woods CP, Austin RT, Bacmeister J, Chern J, Del Genio A, Jiang $J H$, Kuang Z, Meng H, Minnis P, Platnick S, Rossow WB, Stephens GL, SunMack S, Tao W, Tompkins AM, Vane DG, Walker C, Wu D (2009) Cloud ice: a climate model challenge with signs and expectations of progress. J Geophys Res 114:D00A21. doi:10.1029/2008JD010015

Walther A, Heidinger AK (2012) Implementation of the daytime cloud optical and microphysical properties algorithm (DCOMP) in PATMOS-x. J Appl Meteorol Climatol 51:1371-1390

Wan Z, Li ZL (1997) A physics-based algorithm for retrieving land-surface emissivity and temperature from EOS/MODIS data. IEEE Trans Geosci Remote Sens 35:980-996. doi:10.1109/36.602541

Wan Z, Zhang Y, Zhang Q, Li ZL (2004) Quality assessment and validation of the MODIS global land surface temperature. Int J Remote Sens 25:261-274

Wang W, Liang S, Meyers T (2008) Validating MODIS land surface temperature products using long-term nighttime ground measurements. Remote Sens Environ 112:623-635
Wang C, Platnick S, Zhang Z, Meyer K, Yang P (2016) Retrieval of ice cloud properties using an optimal estimation algorithm and MODIS infrared observations: 1. Forward model, error analysis, and information content. J Geophys Res. doi:10.1002/2015JD024526

Watts PD, Bennartz R, Fell F (2011) Retrieval of two-layer cloud properties from multispectral observations using optimal estimation. J Geophys Res 116: D16203. doi:10.1029/2011JD015883

Wiscombe W (1977) The delta-M method: rapid yet accurate radiative flux calculations for strongly asymmetric phase functions. J Atmos Sci 34:1408-1422

Yang P, Bi L, Baum BA, Liou KN, Kattawar GW, Mishchenko MI, Cole B (2013) Spectrally consistent scattering, absorption, and polarization properties of atmospheric ice crystals at wavelengths from 0.2 to $100 \mu \mathrm{m}$. J Atmos Sci 70: 330-347. doi:10.1175/JAS-D-12-039.1

\section{Submit your manuscript to a SpringerOpen ${ }^{\circ}$ journal and benefit from:}

- Convenient online submission

- Rigorous peer review

- Immediate publication on acceptance

- Open access: articles freely available online

- High visibility within the field

- Retaining the copyright to your article

Submit your next manuscript at $>$ springeropen.com 